\title{
Article \\ Degradation of Benzene Using Dielectric Barrier Discharge Plasma Combined with Transition Metal Oxide Catalyst in Air
}

\author{
Yuwei Li ${ }^{1}$, Hao Yuan ${ }^{2}$, Xiongfeng Zhou ${ }^{2}$, Jianping Liang ${ }^{2}$, Yueyue Liu ${ }^{1}$, Dalei Chang ${ }^{1, *}$ (i) \\ and Dezheng Yang 1,2,3,*(D) \\ 1 School of Sciences, Shihezi University, Shihezi 832003, China; liyu2021320@163.com (Y.L.); \\ yueyue_12021@163.com (Y.L.) \\ 2 Key Laboratory of Materials Modification by Laser, Ion, and Electron Beams, Ministry of Education, \\ Dalian University of Technology, Dalian 116024, China; yuanhao@dlut.edu.cn (H.Y.); \\ zhouxiongfeng@mail.dlut.edu.cn (X.Z.); liangjp0601@mail.dlut.edu.cn (J.L.) \\ 3 Key Laboratory of Environmental Monitoring and Pollutant Control of Xinjiang Bingtuan, Shihezi University, \\ Shihezi 832003, China \\ * Correspondence: chang-da-lei@163.com (D.C.); yangdz@dlut.edu.cn (D.Y.)
}

Citation: Li, Y.; Yuan, H.; Zhou, X.; Liang, J.; Liu, Y.; Chang, D.; Yang, D. Degradation of Benzene Using Dielectric Barrier Discharge Plasma Combined with Transition Metal Oxide Catalyst in Air. Catalysts 2022, 12, 203. https://doi.org/10.3390/ catal12020203

Academic Editor: Andrea Biffis

Received: 13 December 2021

Accepted: 25 January 2022

Published: 8 February 2022

Publisher's Note: MDPI stays neutral with regard to jurisdictional claims in published maps and institutional affiliations.

Copyright: (C) 2022 by the authors. Licensee MDPI, Basel, Switzerland. This article is an open access article distributed under the terms and conditions of the Creative Commons Attribution (CC BY) license (https:// creativecommons.org/licenses/by/ $4.0 /)$.

\begin{abstract}
In this paper, a uniform and stable dielectric barrier discharge plasma is presented for degradation of benzene combined with a transition metal oxide catalyst. The discharge images, waveforms of discharge current, and the optical emission spectra are measured to investigate the plasma characteristics. The effects of catalyst types, applied voltage, driving frequency, and initial VOCs concentration on the degradation efficiency of benzene are studied. It is found that the addition of the packed dielectric materials can effectively improve the uniformity of discharge and enhance the intensity of discharge, thus promoting the benzene degradation efficiency. At $22 \mathrm{kV}$, the degradation efficiencies of dielectric barrier discharge plasma packed with $\mathrm{CuO}, \mathrm{ZnO}$ and $\mathrm{Fe}_{3} \mathrm{O}_{4}$ are 93.6\%, 93.2\% and $76.2 \%$, respectively. When packing with $\mathrm{ZnO}$, the degradation efficiency of the dielectric barrier discharge plasma is improved from $86.8 \%$ to $94.9 \%$, as the applied voltage increases from $16 \mathrm{kV}$ to $24 \mathrm{kV}$. The catalysts were characterized by XPS, XRD and SEM. The synergistic mechanism and the property of the catalyst are responsible for benzene degradation in the plasma-catalysis system. In addition, the main physiochemical processes and possible degradation mechanism of benzene are discussed.
\end{abstract}

Keywords: DBD; non-thermal plasma; transition metal oxide catalyst; benzene degradation

\section{Introduction}

Volatile organic compounds (VOCs) lead to vast human diseases and environmental problems [1-3]. Humans exposed to VOCs for a long time can suffer from respiratory disorders, cardiovascular diseases, and cancer [4]. Moreover, VOCs reacting with other gaseous pollutants is the main cause of ozone layer depletion and photochemical smog [5]. Tremendous efforts have been devoted to the investigation of VOC degradation technologies, including adsorption, biological decomposition, catalytic oxidation, non-thermal plasma (NTP), etc. [6-8].

In the last two decades, the degradation of VOCs by NTP has attracted the attention of researchers for the advantages of high removal efficiency, easy operation, low reaction temperature, etc. [9]. In NTP, strong electric field selectively accelerates electrons to become high-energy electrons, which collide with gas molecules to produce plenty of reactive species [10]. These reactive species, including energetic electrons, ions, radicals and excited molecules and atoms, generated in the NTP can degrade the VOCs through complex physicochemical reactions into small molecule species, such as $\mathrm{CO}_{2}$ and $\mathrm{H}_{2} \mathrm{O}$ [11].

NTP combined with a catalyst can improve the degradation efficiency of VOCs further due to the synergistic effect [12]. Zhang et al. [13] presented a dielectric barrier discharge 
(DBD) reactor filled with $\mathrm{NiO} / \mathrm{Pyr}$ composite system, and found it could dramatically improve the removal efficiency of gaseous styrene compared with a bare DBD system. Nguyen et al. [14] compared a plasma combined with Pd /ZSM-5 catalyst system with a plasma alone system. The results show that the former significantly enhanced the styrene degradation efficiency. On the one hand, a packed bed structure is formed by introducing a catalyst into the plasma reactor. The addition of the packing material strongly enhances the intensity of discharge and highly improves the uniformity of discharge, hence improving the VOCs degradation efficiency [15]. On the other hand, the filling materials in the NTP reactor can produce more active species on the surfaces of catalysts [16]. Mao et al. [7] carried out experiments that used the plasma catalyst reactor and the $\mathrm{O}_{3}$ catalyst reactor. The results show that on the $\mathrm{CeO}_{2}$ catalyst's surface, $\mathrm{O}_{3}$ can be degraded into $\mathrm{O}_{2}{ }^{2-}$ and $\mathrm{O}^{2-}$ radicals.

The transition metal oxides, $\mathrm{ZnO}, \mathrm{MnO}_{\mathrm{x}}, \mathrm{NiO}, \mathrm{CuO}$, etc., have attracted great attention owing to their low cost, high catalytic activity, anti-toxicity and wide range of available sources [17-19]. In experiments introducing the $\mathrm{MnO}_{\mathrm{x}}$ catalyst to the plasma reactor, the xylene removal efficiency was strongly improved [19]. Yan et al. [20] investigated nano- $\mathrm{ZnO}$ for bisphenol A degradation in a DBD system, and found that $\mathrm{ZnO}$ has a multicatalysis effects: as a photocatalyst to generate the radical $\mathrm{OH}$, and as a catalyst to react with $\mathrm{O}_{3}$ and $\mathrm{H}_{2} \mathrm{O}_{2}$ to form $\mathrm{OH}$. Rostami et al. [21] found that the highest benzene removal efficiency was $52.7 \pm 1.9 \%$ in the $\mathrm{CuO}$-coated electrode reactor. However, there have been few studies comparing the synergistic effects of several transition metal oxides in the NTP-catalysis system.

In this study, benzene is chosen as the target VOCs contaminant, and the degradation of benzene by synergy $\mathrm{DBD} / \mathrm{CuO}, \mathrm{DBD} / \mathrm{ZnO}$ and $\mathrm{DBD} / \mathrm{Fe}_{3} \mathrm{O}_{4}$ is investigated. The discharge images and the waveforms of voltage and current are discussed. The reactive species are diagnosed using optical emission spectra (OES). The effects of applied voltage, driving frequency and initial concentration of VOCs on the performance of benzene removal are studied. Finally, the main physiochemical processes and the benzene degradation pathway are analyzed in the DBD catalytic system.

\section{Results and Discussion}

\subsection{Visualization and Electrical Characteristics of $D B D$}

Figure 1 shows the discharge images of the DBD without and with packed $\mathrm{CuO}$ under various applied voltages. A Cannon 70D digital camera is used for capturing the discharge images with an exposure time of $1 \mathrm{~s}$, as the total synthetic air flow is $500 \mathrm{~mL} / \mathrm{min}$ and the driving frequency is $8 \mathrm{kHz}$. The discharge images of DBD without catalysts are shown in Figure 1a, where only a weak surface discharge with purple coloration occurred on the outer dielectric tube at $22 \mathrm{kV}$, and when the applied voltage was lower than $20 \mathrm{kV}$, the gas gap did not break down. When the voltage applied was $24 \mathrm{kV}$, it produced weak plasma between the inner quartz tube and the high-voltage probe, except for the surface discharge on the outer dielectric tube. Figure $1 \mathrm{~b}$ shows DBD packed with $\mathrm{CuO}$ catalyst, wherein a fuse discharge can be generated in the region of the packed catalyst at $16 \mathrm{kV}$. The discharge was gradually brightened and remained diffused and stable as the applied voltage increased. It is evident that the discharge region of the $\mathrm{DBD}$ packed with $\mathrm{CuO}$ is much larger than that without catalyst. Obviously, the addition of the catalyst significantly reduces the breakdown voltage and increases the discharge volume into the whole packed region. One of the reasons for this is that the catalyst decreases the discharge gap and increases the reduced electric filed $\mathrm{E} / \mathrm{N}$ due to the reductions in the gas molecules, thus reducing the breakdown voltage [22]. Furthermore, charge accumulates on the surfaces of the catalysts, and the electric field is stronger at the contact points between catalyst particles and between the catalyst and the DBD reactor tubes, which makes it easier to discharge [23]. 

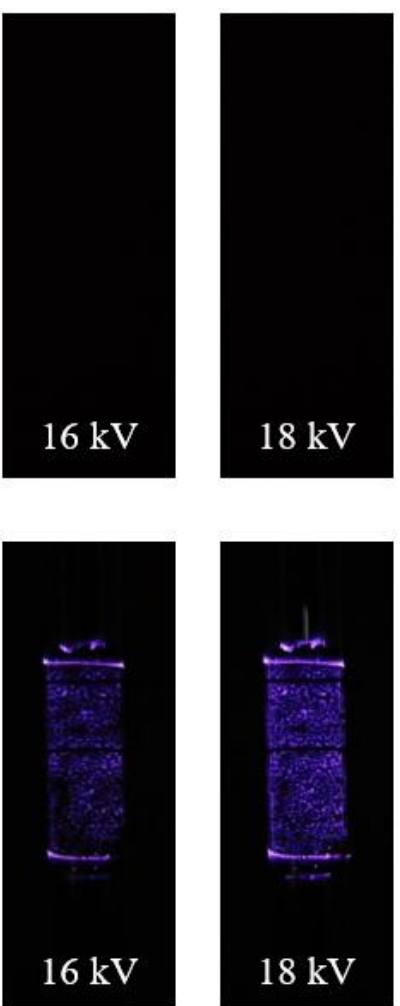
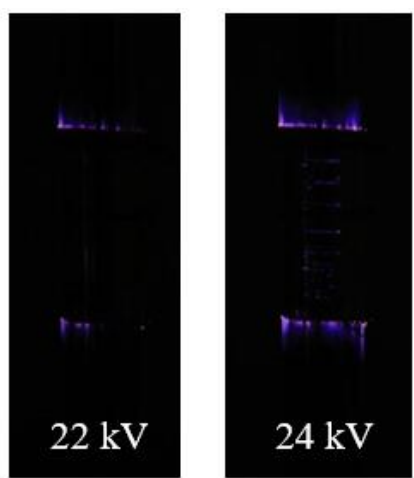

(a)
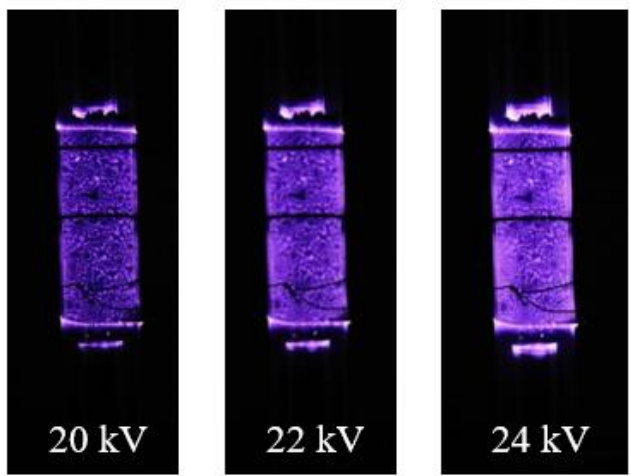

(b)

Figure 1. The effects of the applied voltage on discharge images of the DBD (a) without catalyst and (b) packed with $\mathrm{CuO}$ catalyst in synthetic air at $8 \mathrm{kHz}$.

In $\mathrm{DBD}$, the gas is broken down at a random location when the applied electric field is larger than the gas breakdown electric field. Discharge channels tend to constrict, and form distinct plasma discharge filaments according to the streamer breakdown mechanism [24]. Figure 2 presents the waveforms of the voltage and current of the DBD reactor without and with packed $\mathrm{ZnO}$ catalyst. The driving frequency was kept at $14 \mathrm{kHz}$. The discharge current filaments of DBD without and with packed $\mathrm{ZnO}$ in $24 \mathrm{kV}$ were as shown in Figure $2 \mathrm{a}$, c; the strength of the current pulses apparently increased with the addition of catalyst, while the current peak decreased from about $0.5 \mathrm{~A}$ to about $0.15 \mathrm{~A}$. This phenomenon is related to the filling materials significantly reducing the discharge volume, which means the distance of a typical micro-discharge transition reduces [22]. Furthermore, a strong electric field is produced in neighboring regions of contact points between the catalyst particles [25]. The stronger the local electric field, the easier it is for the gas to break down. As such, the microdischarge is enhanced and the current peak decreases. Figure $2 b$ presents the waveforms of the voltage and current in the DBD reactor with $\mathrm{ZnO}$ catalyst at $16 \mathrm{kV}$. Comparing Figure $2 b, c$, we see that the amount and the intensity of current pulses increased significantly with increase in the applied voltage, while the current peak decreased from about $0.3 \mathrm{~A}$ to $0.15 \mathrm{~A}$. This may be because the electric field in the gas gap and on the catalyst's surface increased with the voltage applied in this condition [26]. Electrons gain more energy from the high electric field, causing more collisions, dissociations and ionizations, and thus more micro-discharges [27]. Since the power supply was constant, when the applied voltage increased to a certain point, the current did not increase, which may be the reason for the reductions in peak current. 


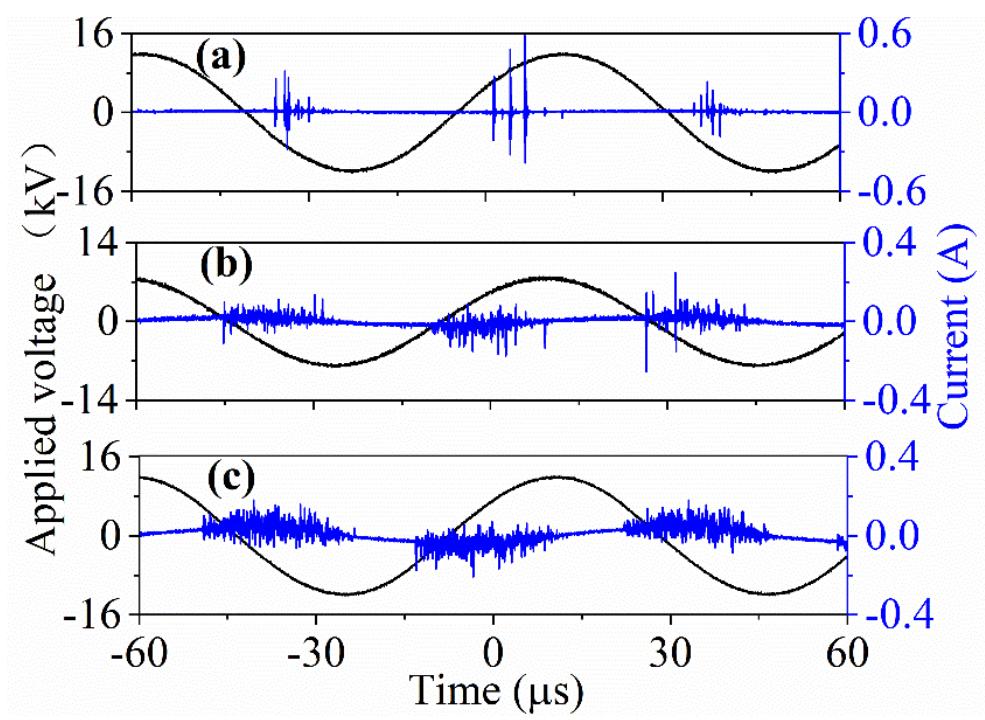

Figure 2. The typical waveforms of voltage and current of a DBD reactor under the conditions of a $14 \mathrm{kHz}$ driving frequency in synthetic air: (a) without catalyst at $24 \mathrm{kV}$; (b) packed with $\mathrm{ZnO}$ at $16 \mathrm{kV}$; (c) packed with $\mathrm{ZnO}$ at $24 \mathrm{kV}$.

\subsection{The Power of the Discharge in DBD}

The discharge power of different catalysts varying with applied voltage is presented in Figure 3. The discharge power of the DBD packed with three catalysts increased with the increasing of the applied voltage. At $16 \mathrm{kV}$, the discharge power of DBD packed with $\mathrm{ZnO}, \mathrm{CuO}$, and $\mathrm{Fe}_{3} \mathrm{O}_{4}$ was $4.3 \mathrm{~W}, 2.6 \mathrm{~W}$, and $2.3 \mathrm{~W}$, respectively. When the applied voltage increased to $24 \mathrm{kV}$, the discharge power of DBD packed with $\mathrm{ZnO}, \mathrm{CuO}$, and $\mathrm{Fe}_{3} \mathrm{O}_{4}$ can reach $22 \mathrm{~W}, 18.7 \mathrm{~W}$, and $12.4 \mathrm{~W}$, respectively.

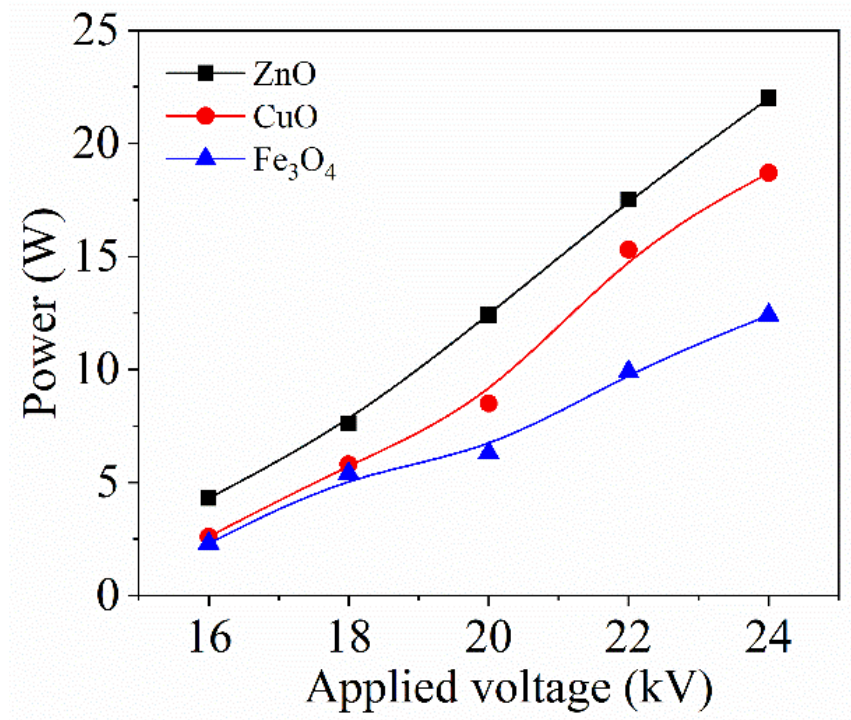

Figure 3. Discharge power of DBD reactor packed with $\mathrm{ZnO} / \mathrm{CuO} / \mathrm{Fe}_{3} \mathrm{O}_{4}$ as catalyst varying with voltage applied at $14 \mathrm{kHz}$ driving frequency in the synthetic air.

\subsection{Emission Spectra of the Discharge in $D B D$}

The OES emitted by the DBD packed with $\mathrm{ZnO}$ in synthetic air is shown in Figure 4. The applied voltage was $18 \mathrm{kV}$, and the driving frequency was $14 \mathrm{kHz}$ in the experiment. It is clearly that the spectra of the DBD are composed of $N_{2}\left(C^{3} \Pi_{u} \rightarrow B^{3} \Pi_{g}\right)$, $\mathrm{N}_{2}\left(\mathrm{~B}^{3} \Pi_{\mathrm{g}} \rightarrow \mathrm{A}^{3} \Pi_{\mathrm{u}}^{+}\right), \mathrm{N}_{2}^{+}\left(\mathrm{B}^{2} \Sigma_{\mathrm{u}}^{+} \rightarrow \mathrm{X}^{2} \Sigma_{\mathrm{g}}^{+}\right)$, and the spectral line of oxygen atoms 
$\mathrm{O}\left(3 p^{5} \mathrm{P} \rightarrow 3 s^{5} \mathrm{~S}_{2}^{\mathrm{o}}\right)$. Similar emission spectra have also been identified in other atmospheric air discharge studies [28]. The spectra peak of $N_{2}\left(C^{3} \Pi_{u} \rightarrow B^{3} \Pi_{g}\right)$ is highest due to the fact that $\mathrm{N}_{2}$ constitutes three quarters of the synthetic air, and the energetic electrons directly collide with $\mathrm{N}_{2}$ molecules, the excitation threshold of which is about $11 \mathrm{eV}$, leading dominantly to $\mathrm{N}_{2}\left(\mathrm{C}^{3} \Pi_{\mathrm{u}}\right)$ become excited. The corresponding reactions are as follows [29]:

$$
\begin{gathered}
\mathrm{e}+\mathrm{N}_{2}\left(\mathrm{X}^{1} \Sigma_{\mathrm{g}}^{+}\right) \rightarrow \mathrm{e}+\mathrm{N}_{2}\left(\mathrm{C}^{3} \Pi_{\mathrm{u}}\right), 7.9 \times 10^{-11} \mathrm{~cm}^{3} \mathrm{~s}^{-1} \\
\mathrm{~N}_{2}\left(\mathrm{C}^{3} \Pi_{\mathrm{u}}\right) \rightarrow \mathrm{N}_{2}\left(\mathrm{~B}^{3} \Pi_{\mathrm{g}}\right)+\mathrm{hv}, 3 \times 10^{-7} \mathrm{~cm}^{3} \mathrm{~s}^{-1} \\
\mathrm{~N}_{2}\left(\mathrm{~A}^{3} \Sigma_{\mathrm{u}}^{+}\right)+\mathrm{N}_{2}\left(\mathrm{~A}^{3} \Sigma_{\mathrm{u}}^{+}\right) \rightarrow \mathrm{N}_{2}\left(\mathrm{C}^{3} \Sigma_{\mathrm{u}}\right)+\mathrm{N}_{2}, 2.1 \times 10^{-12} \mathrm{~cm}^{3} \mathrm{~s}^{-1}
\end{gathered}
$$
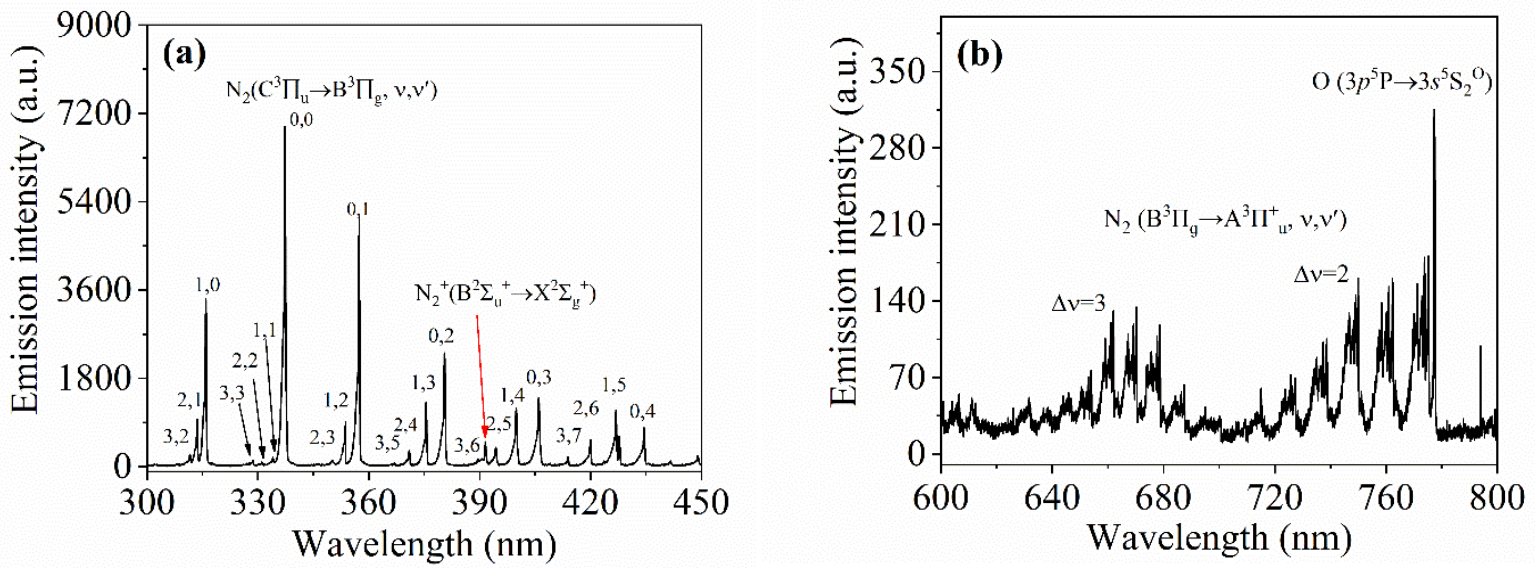

Figure 4. Typical emission spectra: (a) 300-450 nm and (b) 600-800 nm emitted from the DBD packed with $\mathrm{ZnO}$ as a catalyst at $18 \mathrm{kV}$ and $14 \mathrm{kHz}$ in synthetic air.

Energetic electrons (about $18.7 \mathrm{eV}$ ), mainly positioned at the streamer head, can directly excite the $\mathrm{N}_{2}$ molecules to $\mathrm{N}_{2}^{+}\left(\mathrm{B}^{2} \Sigma_{\mathrm{u}}^{+}\right)$[30].

$$
\begin{gathered}
\mathrm{e}+\mathrm{N}_{2}\left(\mathrm{X}^{1} \Sigma_{\mathrm{g}}^{+}\right) \rightarrow 2 \mathrm{e}+\mathrm{N}_{2}^{+}\left(\mathrm{B}^{2} \Sigma_{\mathrm{u}}^{+}\right) \\
\mathrm{e}+\mathrm{N}_{2}\left(\mathrm{~A}^{3} \Sigma_{\mathrm{u}}^{+}\right) \rightarrow 2 \mathrm{e}+\mathrm{N}_{2}^{+}\left(\mathrm{B}^{2} \Sigma_{\mathrm{u}}^{+}\right), 2.4 \times 10^{-12} \mathrm{~cm}^{3} \mathrm{~s}^{-1}
\end{gathered}
$$

The process of forming $\mathrm{O}\left(3 p^{5} \mathrm{P}\right)$ is as follows: [23]

$$
\begin{gathered}
\mathrm{e}+\mathrm{O}_{2} \rightarrow \mathrm{e}+\mathrm{O}\left({ }^{3} \mathrm{P}\right)+\mathrm{O}\left({ }^{1} \mathrm{~S}\right), \log k=-8.8-11.9 / \Theta \\
\mathrm{N}_{2}\left(\mathrm{~A}^{3} \Sigma_{\mathrm{u}}^{+}\right)+\mathrm{O}_{2} \rightarrow \\
\mathrm{N}_{2}\left(\mathrm{X}^{1} \Sigma_{\mathrm{g}}^{+}\right)+\mathrm{O}+\mathrm{O}, 2.54 \times 10^{-11} \mathrm{~cm}^{3} \mathrm{~s}^{-1} \\
\mathrm{e}+\mathrm{O} \rightarrow \mathrm{e}+\mathrm{O}\left(3 p^{5} \mathrm{P}\right)
\end{gathered}
$$

Figure $5 \mathrm{a}$ presents the effects of discharge time on the emission intensity of $\mathrm{N}_{2}$ $\left(\mathrm{C}^{3} \Pi_{\mathrm{u}} \rightarrow \mathrm{B}^{3} \Pi_{\mathrm{g}}\right), \mathrm{N}_{2}^{+}\left(\mathrm{B}^{2} \Sigma_{\mathrm{u}}^{+} \rightarrow \mathrm{X}^{2} \Sigma_{\mathrm{g}}^{+}\right)$and $\mathrm{O}\left(3 p^{5} \mathrm{P} \rightarrow 3 s^{5} \mathrm{~S}_{2}^{\mathrm{o}}\right)$ emitted from DBD packed with $\mathrm{ZnO}$. It is shown that the intensity of the three active species remains almost unchanged within $12 \mathrm{~min}$ of the discharge duration time. This phenomenon indicates the good stability of the packed bed DBD. The emission intensities of $\mathrm{N}_{2}\left(\mathrm{C}^{3} \Pi_{\mathrm{u}} \rightarrow \mathrm{B}^{3} \Pi_{\mathrm{g}}\right)$, $\mathrm{N}_{2}^{+}\left(\mathrm{B}^{2} \Sigma_{\mathrm{u}}^{+} \rightarrow \mathrm{X}^{2} \Sigma_{\mathrm{g}}^{+}\right)$and $\mathrm{O}\left(3 p^{5} \mathrm{P} \rightarrow 3 s^{5} \mathrm{~S}_{2}^{\mathrm{o}}\right)$, varying with the applied voltage and driving frequency, are presented in Figures $5 b, c$, respectively. The results show that with 
the increment in both applied voltage and driving frequency, the emission intensities of $\mathrm{N}_{2}\left(\mathrm{C}^{3} \Pi_{\mathrm{u}} \rightarrow \mathrm{B}^{3} \Pi_{\mathrm{g}}\right), \mathrm{N}_{2}^{+}\left(\mathrm{B}^{2} \Sigma_{\mathrm{u}}^{+} \rightarrow \mathrm{X}^{2} \Sigma_{\mathrm{g}}^{+}\right)$and $\mathrm{O}\left(3 p^{5} \mathrm{P} \rightarrow 3 s^{5} \mathrm{~S}_{2}^{\mathrm{o}}\right)$ all rise. When the driving frequency is kept constant, an increasing applied voltage leads to a rise in electron mean energy [31]. When the applied voltage is kept constant, increasing the driving frequency leads to an increases in the amount of micro-discharges in a set period of time, which also leads to an increases in the high-energy electron density [32]. The electrons, ions, molecules, and atoms collide more frequently, which leads to the number of excited particles increasing. Thus, the emission intensities of the active species are increased when increasing both the voltage and the frequency.
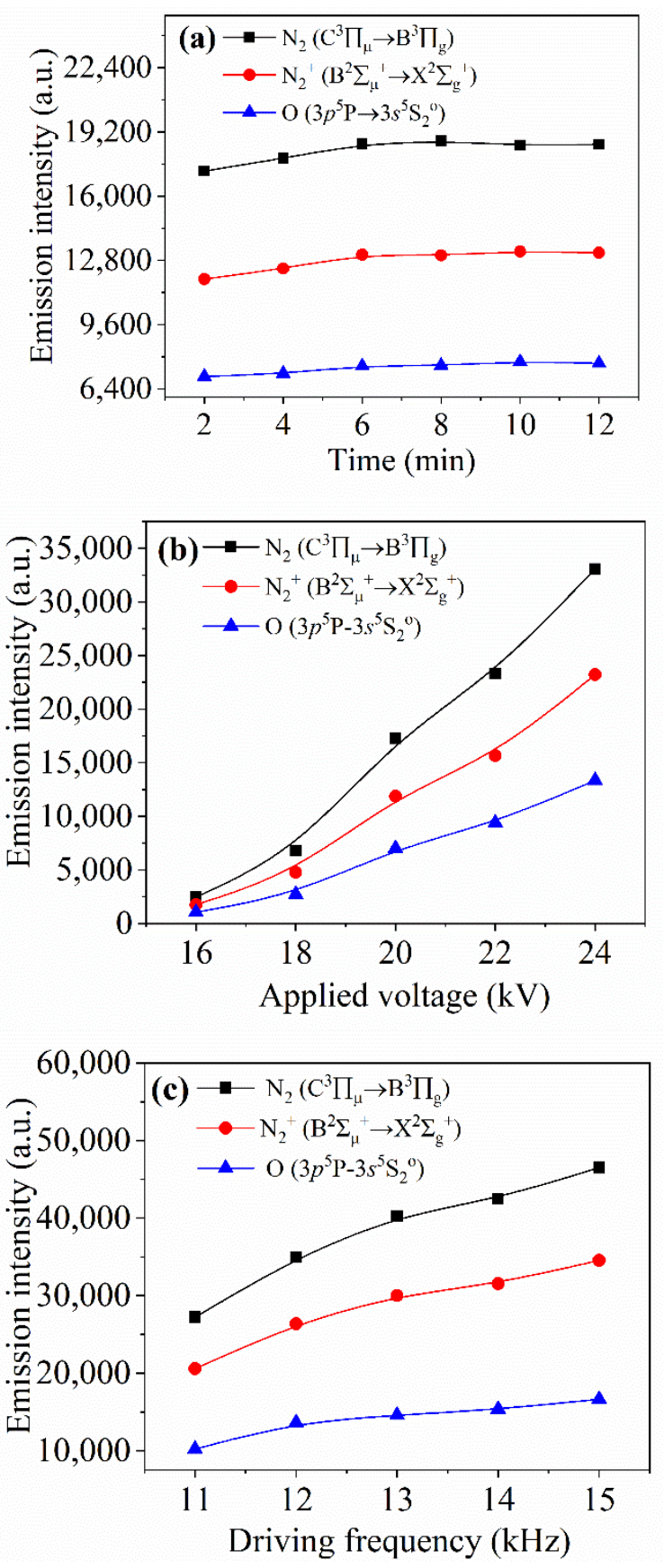

Figure 5. The emission intensity of $\mathrm{N}_{2} \quad\left(\mathrm{C}^{3} \Pi_{\mathrm{u}} \rightarrow \mathrm{B}^{3} \Pi_{\mathrm{g}}\right), \mathrm{N}_{2}^{+} \quad\left(\mathrm{B}^{2} \Sigma_{\mathrm{u}}^{+} \rightarrow \mathrm{X}^{2} \Sigma_{\mathrm{g}}^{+}\right)$and $\mathrm{O}\left(3 p^{5} \mathrm{P} \rightarrow 3 s^{5} \mathrm{~S}_{2}^{\mathrm{o}}\right)$ emitted from the DBD packed with $\mathrm{ZnO}$ in the synthetic air: (a) varying with discharge time at $20 \mathrm{kV}$ and $13 \mathrm{kHz}$; (b) varying with applied voltage at $14 \mathrm{kHz}$; (c) varying with driving frequency at $20 \mathrm{kV}$. 


\subsection{The Influence of Different Catalysts on Benzene Decomposition}

Figure 6 shows the effects of DBD combined with different catalysts, $\mathrm{ZnO}, \mathrm{CuO}$ and $\mathrm{Fe}_{3} \mathrm{O}_{4}$, on (a) the benzene degradation efficiency, (b) $\mathrm{CO}_{2}$ selectivity, and (c) energy yield. The initial concentration of benzene is $235 \mathrm{ppm}$, and the benzene-containing air flow rate is $500 \mathrm{~mL} / \mathrm{min}$. It can be noted form Figure $6 \mathrm{a}$ that the benzene removal efficiency increases with the increasing of the applied voltage when the DBD is packed with three catalysts, and the degradation performances of the three types of catalysts are different. At $16 \mathrm{kV}$, the removal efficiency of DBD packed with $\mathrm{ZnO}, \mathrm{Fe}_{3} \mathrm{O}_{4}$ and $\mathrm{CuO}$ is $72.7 \%, 23.4 \%$, and $86.8 \%$, respectively. When the applied voltage increases to $24 \mathrm{kV}$, the degradation efficiency of DBD packed with $\mathrm{ZnO}, \mathrm{Fe}_{3} \mathrm{O}_{4}$ and $\mathrm{CuO}$ can reach $95.3 \%, 80.4 \%$, and $94.9 \%$, respectively. This suggests that increasing the applied voltage can increase the energy injected into the discharge gap. One part of the energy increases the number of energetic electrons, which means the energy is 1-10 eV. A large amount of active species are obtained, such as free radicals $\mathrm{OH}$ and $\mathrm{O}$, through the frequent collision of electrons and background gas molecules [33]. Besides this, the excess energy would transform into heat in the discharge area, and a lot of reactive particles would emit ultraviolet light, which would cause more $\mathrm{O}_{3}$ to transform into reactive atomic oxygen species [34]. Thus, the probability of benzene molecules colliding with reactive particles in the DBD discharge region is enhanced, causing an increase in the degradation efficiency. At a low applied voltage, the degradation efficiencies of benzene by the three catalysts show great differences, and this difference decreases with the increment in voltage. The apparent catalytic activity can be improved by NTP through inducing the dielectric heating of the catalyst [35]. At $16 \mathrm{kV}$, the benzene degradation efficiency of $\mathrm{DBD} / \mathrm{CuO}$ is more than three times that of $\mathrm{DBD} / \mathrm{Fe}_{3} \mathrm{O}_{4}$. This indicates that the synergistic effect of $\mathrm{CuO}$ and NTP is better than that of $\mathrm{ZnO}$ and $\mathrm{Fe}_{3} \mathrm{O}_{4}$ at low applied voltage. When a catalyst is added to the reactor, the ozone produced in the NTP can be fully utilized by the catalyst to form more active oxygenated radicals through catalyst surface reactions [36]. CuO has a good effect on ozone degradation, thus has the best degradation efficiency at the applied voltage (ranging from $16 \mathrm{kV}$ to $22 \mathrm{kV}$ ) [37]. When the reactor is packed with $\mathrm{ZnO}$, the highest benzene degradation efficiency can reach $95.3 \%$, which is slightly higher than when it is packed with $\mathrm{CuO}$ at $24 \mathrm{kV}$. This may be due to the fact that $\mathrm{ZnO}$ is a multi-catalyst, which can be used as a photocatalyst to generate $\mathrm{OH}$, and as the transition metal oxide catalyst to react with $\mathrm{O}_{3}$ [38]. As the applied voltage increases, the UV light produced in the plasma region increases too, via function (2) discussed in the former section, thus better activating the catalysis of the photocatalyst $\mathrm{ZnO}$. High $\mathrm{CO}_{2}$ selectivity is expected because the end products are $\mathrm{CO}_{2}$ and $\mathrm{H}_{2} \mathrm{O}$ in VOC degradation. $\mathrm{CO}_{2}$ selectivity is shown in Figure $6 \mathrm{~b}$. That catalysts have totally different levels of $\mathrm{CO}_{2}$ selectivity may be due to the nature of the catalysts. Although $\mathrm{DBD} / \mathrm{CuO}$ has no obvious advantage in $\mathrm{CO}_{2}$ selectivity, its $\mathrm{CO}_{2}$ concentration is the highest among the three catalysts. The effects of the applied voltage on the EY are shown in Figure 6c. For DBD packed with $\mathrm{ZnO}$ and $\mathrm{CuO}, \mathrm{EY}$ shows a decreasing trend with the increasing of the applied voltage, which decreases from 4.1 to $1 \mathrm{~g} / \mathrm{kWh}$ and 7.5 to $1.1 \mathrm{~g} / \mathrm{kWh}$. This may be due to part of the energy being converted into heat and photons, as well as being used for the formation of byproducts through quenching and recombination reactions [39,40]. It should be noted that unlike $\mathrm{ZnO}$ and $\mathrm{CuO}$, the EY of DBD packed with $\mathrm{Fe}_{3} \mathrm{O}_{4}$ decreases from 2.3 to $1.5 \mathrm{~g} / \mathrm{kWh}$ as the applied voltage increases, but it has a peak value of $2.6 \mathrm{~g} / \mathrm{kWh}$ at $20 \mathrm{kV}$. This is probably because the catalysis of $\mathrm{Fe}_{3} \mathrm{O}_{4}$ is quickly excited at $20 \mathrm{kV}$, at which point the degradation efficiency is significantly increased. 

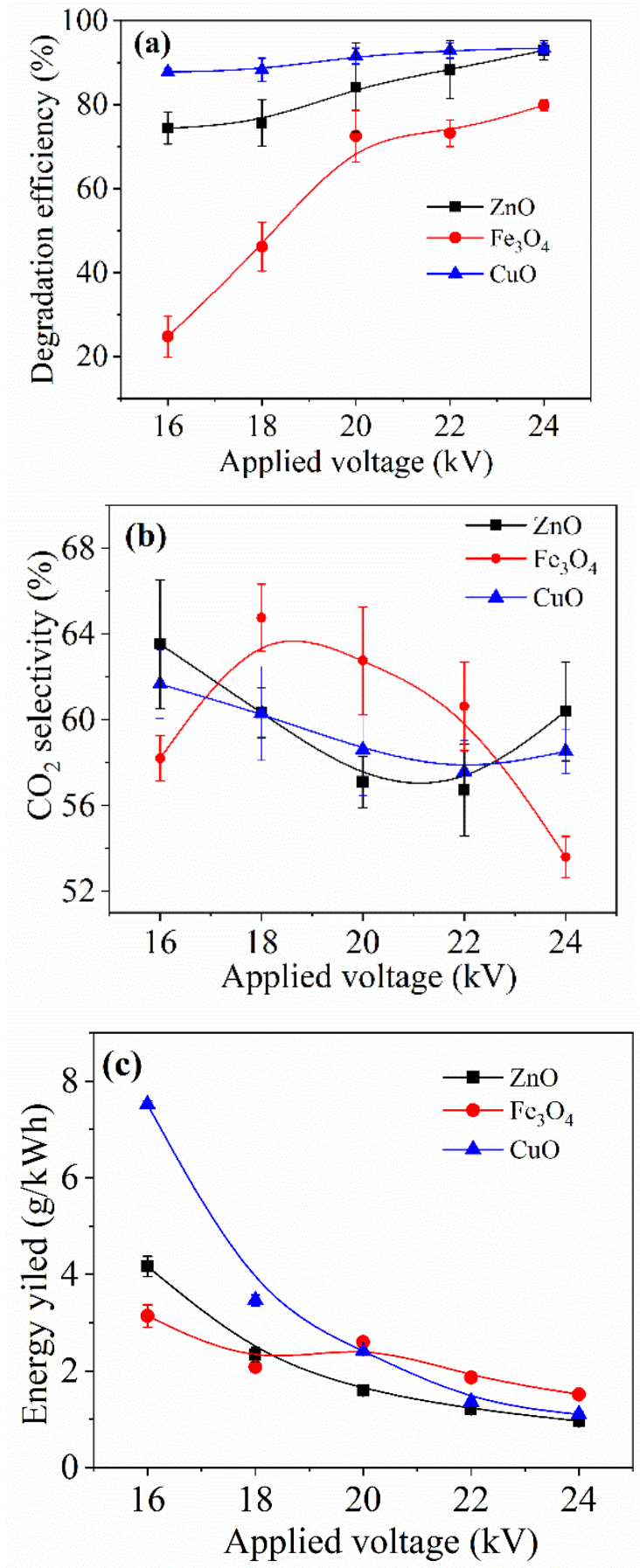

Figure 6. The effects of catalyst on (a) benzene degradation efficiency and (b) $\mathrm{CO}_{2}$ selectivity; (c) energy yield varying with applied voltage when the initial benzene concentration is $235 \mathrm{ppm}$ and the driving frequency is $14 \mathrm{kHz}$.

\subsection{The Influence of Initial Concentration on Benzene Decomposition}

The effects of the initial concentration on the benzene removal efficiency and $\mathrm{CO}_{2}$ selectivity, and the EY varying with the applied voltage in the DBD packed with $\mathrm{ZnO}$ in synthetic air, are depicted in Figure 7 . The driving frequency was kept at $14 \mathrm{kHz}$. The benzene degradation efficiency increased and the EY decreased in response to increasing the applied voltage, regardless of the initial concentration of benzene. The $\mathrm{CO}_{2}$ selectivity presents a decreasing trend with the increase in benzene initial concentration in Figure $7 \mathrm{~b}$. When the initial concentration was fixed at $235 \mathrm{ppm}$, benzene degradation efficiency increased from $72.7 \%$ to $95.3 \%$, with the applied voltage ranging from $16 \mathrm{kV}$ to $24 \mathrm{kV}$, while 
the EY showed the opposite, ranging from $4.1 \mathrm{~g} / \mathrm{kWh}$ to $1 \mathrm{~g} / \mathrm{kWh}$. The removal efficiency of benzene decreased with the increase in initial concentration. At $16 \mathrm{kV}$, the degradation efficiency of benzene reached $100 \%$ when the initial concentration was $60 \mathrm{ppm}$, while the degradation efficiency was $92 \%$ and $79.1 \%$ when the initial concentration was $112 \mathrm{ppm}$ and $235 \mathrm{ppm}$, respectively. Although the benzene degradation efficiency decreased at higher benzene initial concentrations, the amount of converted benzene molecules increased, suggesting more active species are used for the degradation [41]. Under the same applied voltage, when the concentration was increased from $60 \mathrm{ppm}$ to $235 \mathrm{ppm}$, the EY increased, while when the concentration increased to $300 \mathrm{ppm}$, the EY decreased. For example, at $16 \mathrm{kV}$, the EY increased from $1.3 \mathrm{~g} / \mathrm{kWh}$ to $4.1 \mathrm{~g} / \mathrm{kWh}$, and then decreased to $2.8 \mathrm{~g} / \mathrm{kWh}$. For a given applied voltage, a certain number of energetic electrons and reactive species would be produced in the DBD reactor discharge region [13]. When the initial concentration of benzene is lower than a certain value, part of the active species cannot be utilized, and the energy stored in the active species is converted into thermal energy; when the initial concentration is too high, the excess benzene molecules cannot be degraded.
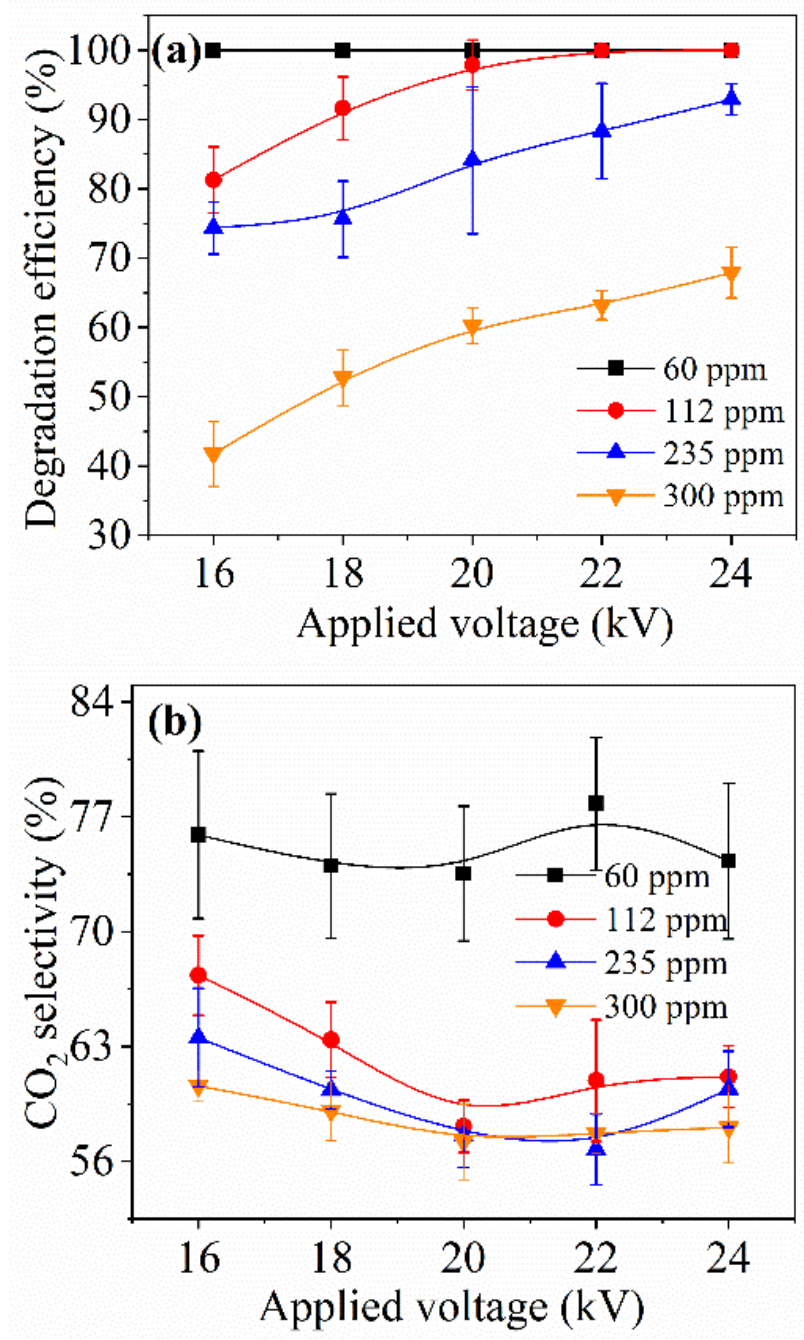

Figure 7. Cont. 


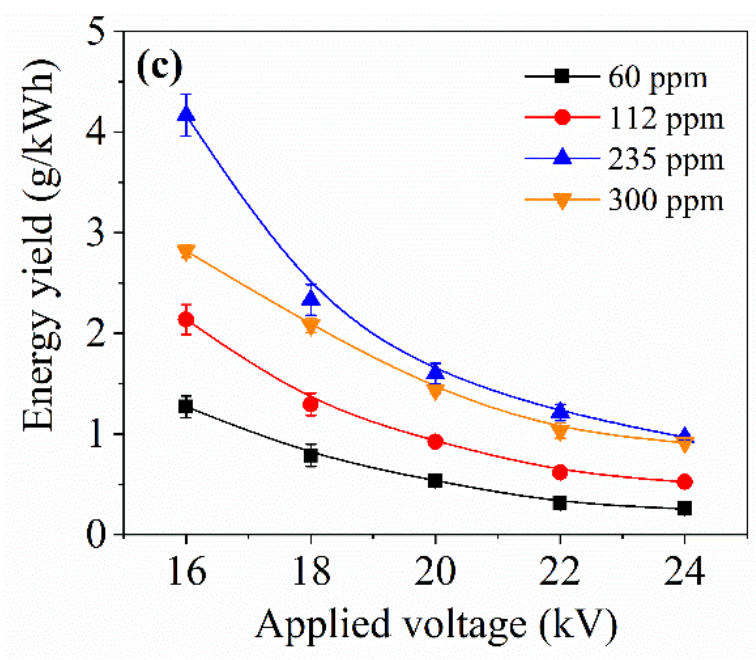

Figure 7. The effects of initial concentration on (a) benzene degradation efficiency and (b) $\mathrm{CO}_{2}$ selectivity; (c) energy yield varying with applied voltage packed with $\mathrm{ZnO}$ at $14 \mathrm{kHz}$ in synthetic air.

\subsection{The Influence of Driving Frequency on Benzene Decomposition}

The effects of driving frequency on the degradation efficiency of benzene and $\mathrm{CO}_{2}$ selectivity, and the EY variation with changes in the applied voltage in the DBD packed with $\mathrm{ZnO}$, are depicted in Figure 8. The initial benzene concentration and the flow rate of the synthetic air are fixed, respectively, at $235 \mathrm{ppm}$ and $500 \mathrm{~mL} / \mathrm{min}$. It is seen that the benzene removal efficiency increased as the applied voltage increased for all the selected driving frequencies. The removal efficiency of benzene increased as the driving frequency increased at a given applied voltage, whereas the corresponding EY decreased. Figure $8 \mathrm{~b}$ shows that the variation in driving frequency had no influence on $\mathrm{CO}_{2}$ selectivity. At $18 \mathrm{kV}$, the benzene degradation efficiency increased from $63 \%$ to $79.1 \%$ as the frequency increased from $12 \mathrm{kHz}$ to $14 \mathrm{kHz}$, while the relevant EY decreased from $4.1 \mathrm{~g} / \mathrm{kWh}$ to $2.3 \mathrm{~g} / \mathrm{kWh}$. This may because more micro-discharges in the DBD reactor would be produced during each period with the increases in the driving frequency, resulting in more reactive species in the discharge region. The probability of collision between the benzene molecules and reactive species is thus increased, contributing to the increases in the benzene degradation efficiency. However, the active species are not fully used, and parts of the active species are quenched and undergo recombination, thus the EY related to benzene degradation decreases [5].

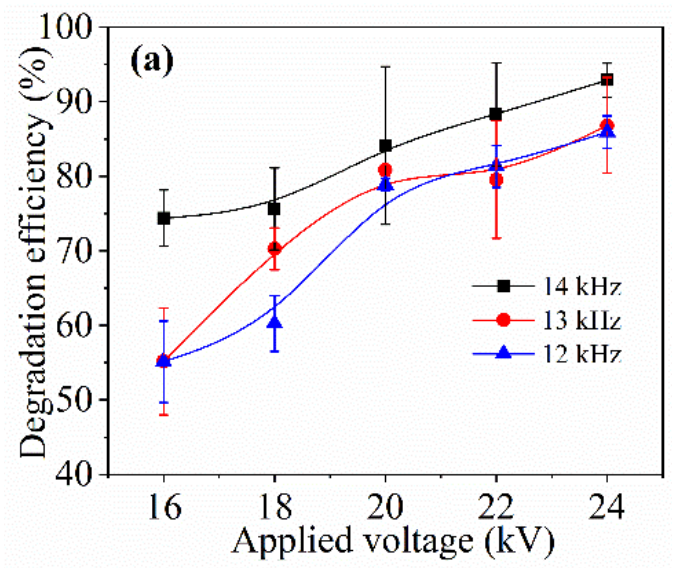

Figure 8. Cont. 

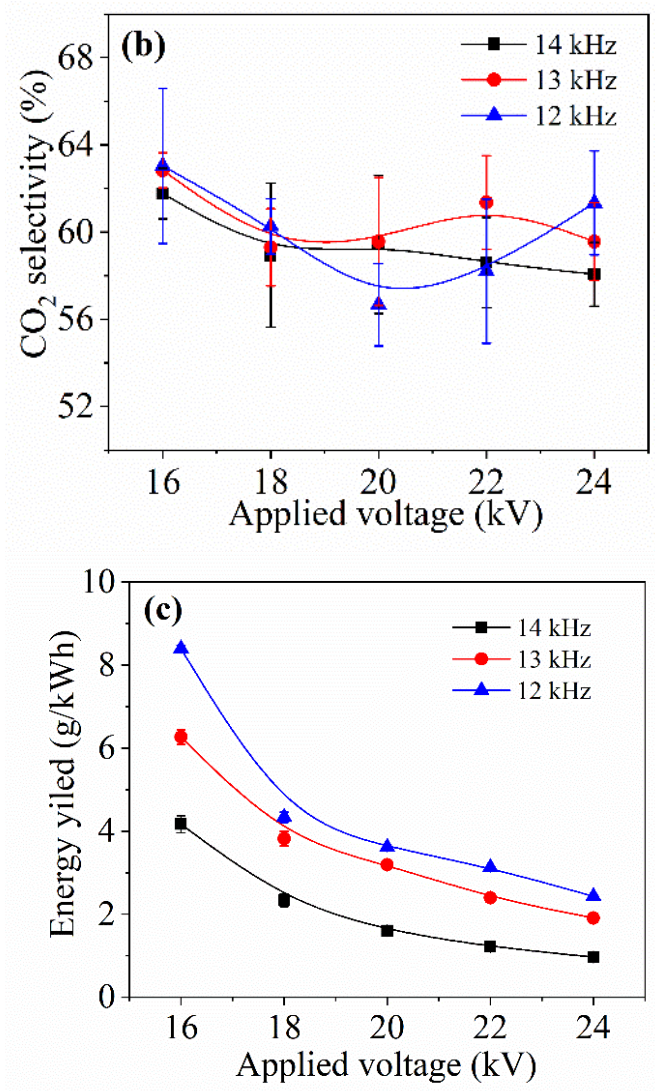

Figure 8. The effects of driving frequency on (a) benzene degradation efficiency and (b) $\mathrm{CO}_{2}$ selectivity; (c) energy yield varying with the applied voltage at the initial benzene concentration of $235 \mathrm{ppm}$ in synthetic air, and packed with $\mathrm{ZnO}$ in the DBD reactor.

\subsection{Characteristics of the Catalysts}

Figure 9 shows the scanning spectra of Cu2p, Zn2p and FeLM2. It can be seen that the spectral lines at $934.6 \mathrm{eV}$ and $954.4 \mathrm{eV}$ correspond to the $\mathrm{Cu} 2 \mathrm{p} 3 / 2$ and $\mathrm{Cu} 2 \mathrm{p} 1 / 2$ of the copper element in $\mathrm{CuO}$, and the shake-up peak at $944 \mathrm{eV}$ indicates the existence of a paramagnetic state in $\mathrm{Cu}^{2+}$. The $\mathrm{Zn} 2 \mathrm{p}$ spectrum's peaks at $1022.6 \mathrm{eV}$ and $1045.8 \mathrm{eV}$ correspond to the $\mathrm{Zn} 2 \mathrm{p} 3 / 2$ and $\mathrm{Zn} 2 \mathrm{p} 1 / 2$ states, which are the normal states of $\mathrm{Zn}^{2+}$ in the $\mathrm{ZnO}$ catalyst [42]. The binding energy of Fe2p3/2, $710.5 \mathrm{eV}$, is quite insignificant compared to the apparent kinetic energy of electrons.

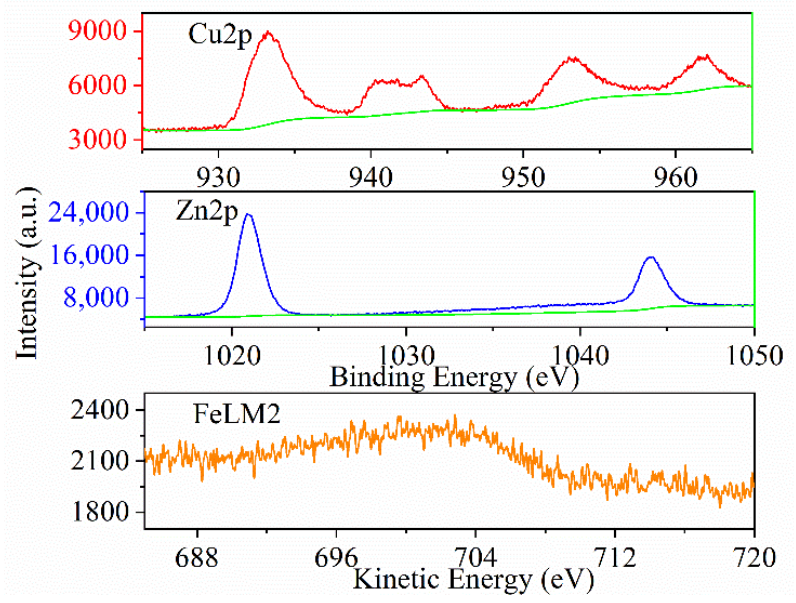

Figure 9. XPS of Cu2p, Zn2p, FeLM2. 
Figure 10 shows the XRD patterns of $\mathrm{CuO}, \mathrm{ZnO}$, and $\mathrm{Fe}_{3} \mathrm{O}_{4}$ catalysts. The diffraction peaks can be observed at a $2 \theta$ of $35.46^{\circ}, 38.60^{\circ}, 48.78^{\circ}, 52.54^{\circ}, 58.42^{\circ}, 61.63^{\circ}, 66.42^{\circ}, 67.93^{\circ}$, $72.38^{\circ}$, and $75.28^{\circ}$, corresponding to the (002), (111), (-202), (202), (-113), (022), (113), (311), and (004) facets of the monoclinic $\mathrm{CuO}$ [43]. As for the $\mathrm{ZnO}$ catalyst, there are 11 diffraction peaks at a $2 \theta$ of $31.8^{\circ}, 34.4^{\circ}, 36.3^{\circ}, 47.5^{\circ}, 56.6^{\circ}, 62.9^{\circ}, 66.4^{\circ}, 68.0^{\circ}, 69.1^{\circ}, 72.6^{\circ}$, and $77.0^{\circ}$ [44]. The peaks of the $\mathrm{Fe}_{3} \mathrm{O}_{4}$ catalyst at $35.5^{\circ}, 43.1^{\circ}, 53.4^{\circ}, 57.0^{\circ}$ and $62.6^{\circ}$ correspond to (311), (400), (422), (511), and (440) in the cubic spinel crystal-structured $\mathrm{Fe}_{3} \mathrm{O}_{4}$ [45]. The peaks at $24.1^{\circ}, 35.6^{\circ}, 57.4^{\circ}, 64.0^{\circ}$, and $66.0^{\circ}$ correspond to the (012), (110), (122), (300), and (125) crystal planes of hexa- $\mathrm{Fe}_{2} \mathrm{O}_{3}[46]$.

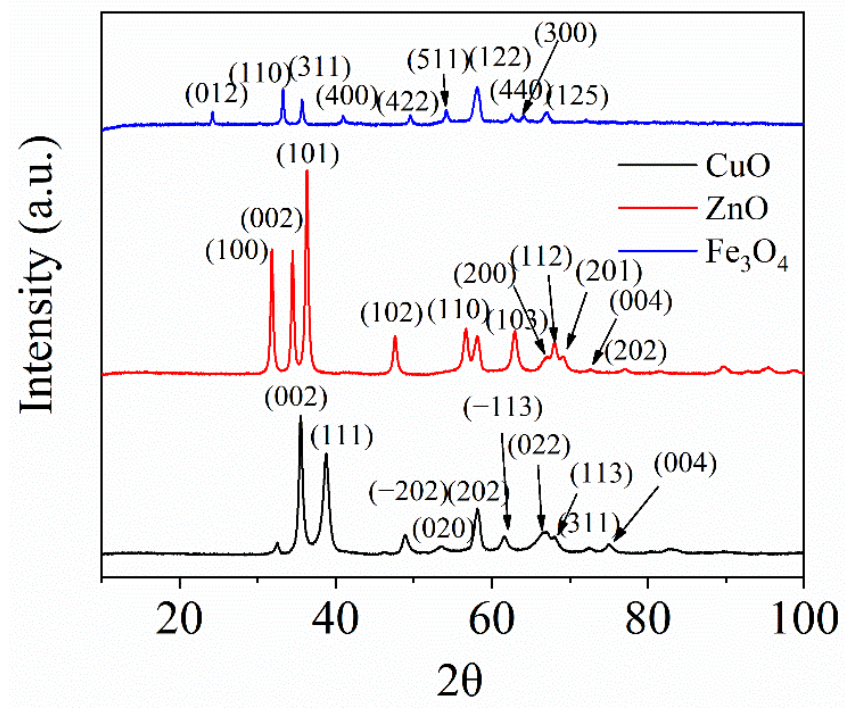

Figure 10. XRD patterns of $\mathrm{CuO}, \mathrm{ZnO}$, and $\mathrm{Fe}_{3} \mathrm{O}_{4}$ catalysts.

SEM micrographs of the three catalysts $\mathrm{CuO}, \mathrm{ZnO}$, and $\mathrm{Fe}_{3} \mathrm{O}_{4}$ are presented in Figure 11. It can be clearly seen from the low magnification scanning that these materials all take the form of very fine particles. Among these catalysts, $\mathrm{CuO}$ has the smallest particle size, and the sizes of $\mathrm{CuO}, \mathrm{ZnO}$, and $\mathrm{Fe}_{3} \mathrm{O}_{4}$ are about $5 \mu \mathrm{m}, 10 \mu \mathrm{m}$, and $20 \mu \mathrm{m}$, respectively.
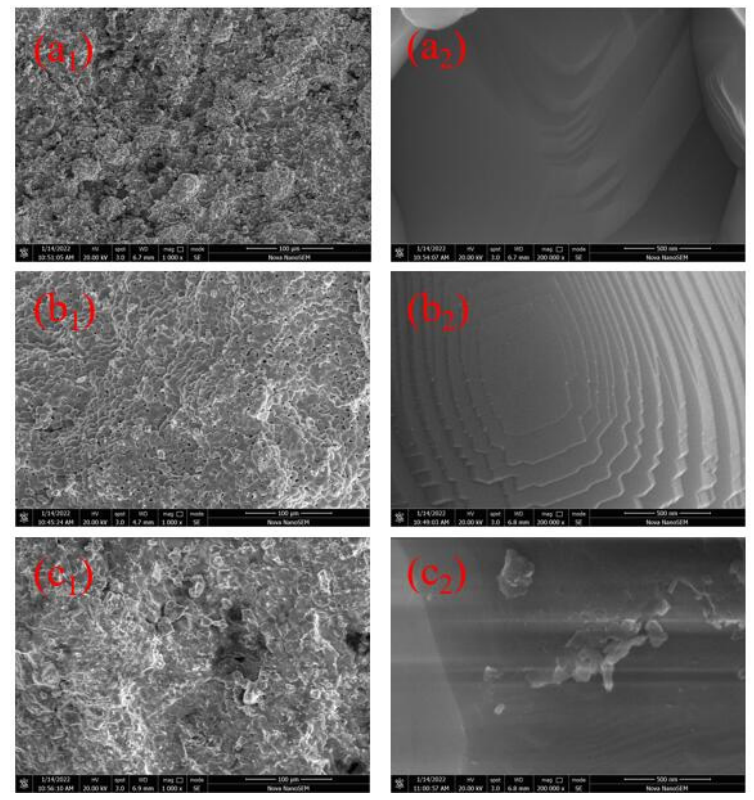

Figure 11. SEM of the $(\mathbf{a} 1, \mathbf{a} 2) \mathrm{CuO},(\mathbf{b 1}, \mathbf{b 2}) \mathrm{ZnO}$, and $(\mathbf{c} 1, \mathbf{c} 2) \mathrm{Fe}_{3} \mathrm{O}_{4}$. 
It can be seen from the above that the three catalysts exist in crystal states. The metal elements of $\mathrm{ZnO}$ and $\mathrm{CuO}$ have higher banding energies, which are relatively more conducive to discharge performance than that of $\mathrm{Fe}_{3} \mathrm{O}_{4}$. The binding energy of $\mathrm{Cu}^{2+}$ is higher than that of $\mathrm{Zn}^{2+}$, and $\mathrm{CuO}$ is more likely to play a photocatalytic role than $\mathrm{ZnO}$. Therefore, $\mathrm{CuO}$ has a better degradation effect on benzene than $\mathrm{ZnO}$ at a lower voltage.

\subsection{Mechanism of Benzene Decomposition}

The benzene degradation efficiency using DBD combined with a catalyst is much higher than that without a catalyst, and $\mathrm{ZnO} / \mathrm{CuO} / \mathrm{Fe}_{3} \mathrm{O}_{4}$ cannot decompose benzene without the correct discharge conditions, implying that DBD and the $\mathrm{ZnO} / \mathrm{CuO} / \mathrm{Fe}_{3} \mathrm{O}_{4}$ catalyst have synergistic effects on benzene degradation. On the one hand, the catalyst can be activated effectively under plasma conditions [47]. The benzene degradation of the catalyst alone in the DBD-packed catalyst reactor has been studied at room temperature. For the three catalysts, no degradation of the benzene, nor any byproduct formation, is observed. On the other hand, the discharge from the DBD can be more uniform, and can generate more active particles, which largely improves the benzene degradation efficiency. The degradation efficiency of bare DBD only is $22.6 \%$ when the applied voltage is $24 \mathrm{kV}$, while benzene does not degrade at all at lower voltages. The interaction of the plasma and catalyst is shown in Figure 12a; the transition metal oxides can strongly promote the decomposition of $\mathrm{O}_{3}$ on the surface of the catalyst to reactive oxygen particles, such as $\mathrm{O}^{-}$and $\mathrm{O}_{2}{ }^{-}$. $\mathrm{ZnO}$ is a photocatalyst, which can absorb UV to generate electrons and holes $\left(\mathrm{e}^{-}\right.$and $\left.\mathrm{h}^{+}\right)$, as well as being a surface that can generate $\mathrm{OH}$ through a sequence of complex chemical reactions [48].

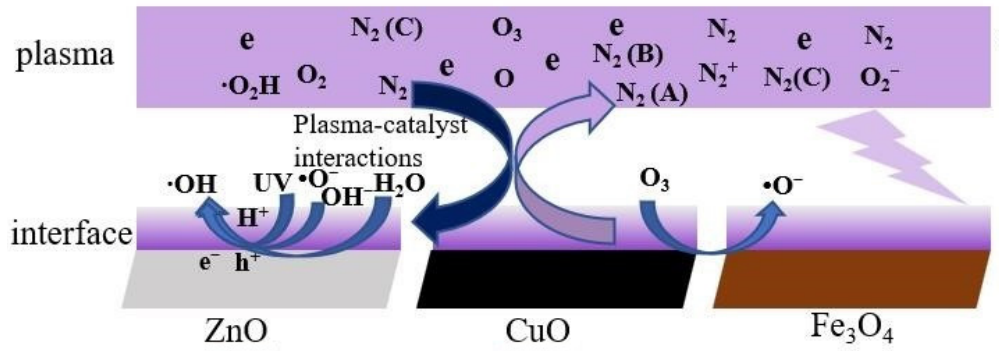

(a)

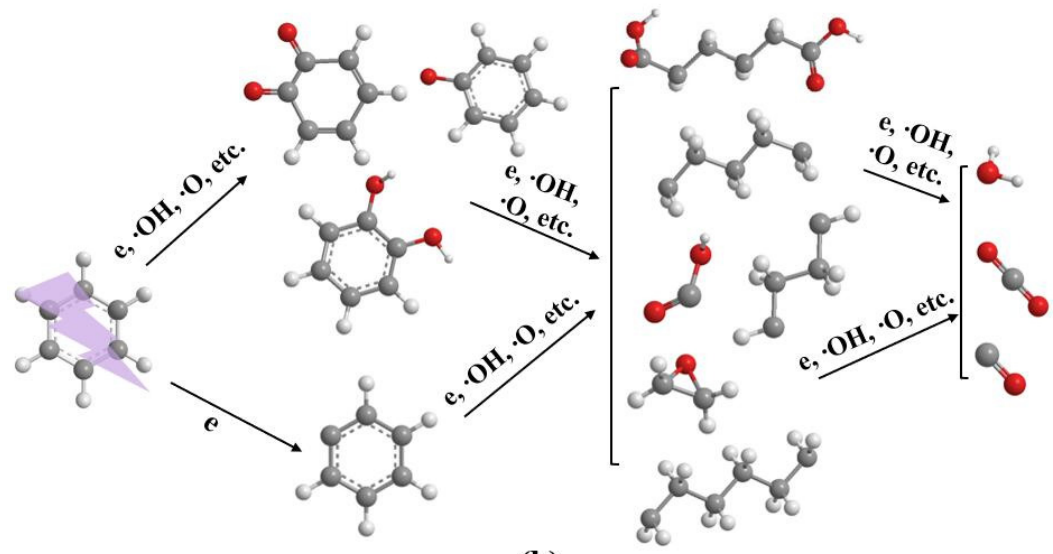

(b)

Figure 12. Pathways of benzene oxidation in DBD packed with catalyst: (a) synergism of the plasma and catalyst; (b) the main reaction of the degradation of benzene.

$$
\begin{gathered}
\mathrm{ZnO}+\mathrm{h} v \rightarrow \mathrm{ZnO}+\mathrm{e}^{-}+\mathrm{h}^{+}, \\
\mathrm{e}^{-}+\mathrm{O}_{3} \rightarrow \bullet \mathrm{O}_{3}^{-}, \\
\bullet \mathrm{O}_{3}^{-} \rightarrow \bullet \mathrm{O}^{-}+\mathrm{O}_{2},
\end{gathered}
$$




$$
\begin{gathered}
\mathrm{h}^{+}+\mathrm{H}_{2} \mathrm{O} \rightarrow \bullet \mathrm{OH}+\mathrm{H}^{+}, \\
\mathrm{h}^{+}+\mathrm{OH}^{-} \rightarrow \bullet \mathrm{OH}, \\
\mathrm{H}^{+}+\bullet \mathrm{O}^{-} \rightarrow \bullet \mathrm{OH},
\end{gathered}
$$

However, the bands of $\mathrm{OH}\left(\mathrm{A}^{2} \Sigma \rightarrow \mathrm{X}^{2} \Pi\right)$ cannot be distinguished, maybe because only small amounts are produced and quickly react with other particles. Furthermore, the discharge is strongly enhanced near the catalyst's surface due to the accumulation of charge on the surface of the dielectric material, which results in more uniform plasma.

The mean energy of electrons accelerated by plasma usually ranges from 1 to $10 \mathrm{eV}$ [49], and energetic electrons can impact molecules in the air, which makes $\mathrm{H}_{2} \mathrm{O}, \mathrm{O}_{2}$, and $\mathrm{N}_{2}$ molecules ionize to form reactive particles, including $\mathrm{O}_{2}{ }^{-}, \mathrm{OH}, \mathrm{N}, \mathrm{O}_{2}{ }^{+}, \mathrm{O}, \mathrm{O}\left({ }^{1} \mathrm{D}\right), \mathrm{O}\left({ }^{3} \mathrm{P}\right)$, $\mathrm{O}^{-}$, etc. [9]. As mentioned above, it is by greatly increasing the number of high-energy electrons and other reactive species that the synergy between plasma and catalyst improves the degradation efficiency of benzene. For the benzene molecule, the dissociation energies of the $\mathrm{C}-\mathrm{C}$ and $\mathrm{C}-\mathrm{H}$ bonds are $5.0-5.5 \mathrm{eV}$ and $4.4 \mathrm{eV}$ [50]. As such, the $\mathrm{C}-\mathrm{H}$ bonds of the benzene molecule are primarily attacked by high-energy electrons and other reactive particles to form phenyl radical, phenol, and o-benzoquinone, as well as other organic byproducts [7]. These derivatives of benzene can be further decomposed into unsaturated linear hydrocarbons and corresponding radicals, as well as organic acids, etc., such as cyclopentadienyl radical, vinylacetylene and 1,3-butadiene. In addition, these benzene derivatives may also polymerize to form aromatic hydrocarbon complex compounds [39]. Finally, these carbon-containing fragments degrade into $\mathrm{CO}, \mathrm{CO}_{2}$ and $\mathrm{H}_{2} \mathrm{O}$ through a series of complex reactions, including hydrogenation and substitution [21,51]. The corresponding main degradation reactions are presented in Figure 12b.

\section{Experimental}

\subsection{Experimental Setup}

The setup diagram of DBD combined with a catalyst degrading benzene is shown in Figure 13. It consists of an AC power supply, a double DBD reactor, a benzene-containing gas generator system, an electric signal acquisition system, an optical diagnosis system, and an exhaust gas detection system. The DBD reactor is composed of two concentric cylindrical quartz glass tubes with different diameters, which are used as inner (outer diameter: $12 \mathrm{~mm}$ ) and outer (outer diameter: $22 \mathrm{~mm}$ ) dielectric barriers (1 $\mathrm{mm}$ thickness). A stainless steel screw is connected to a high voltage (HV) power supply as an $\mathrm{HV}$ electrode with a $10 \mathrm{~mm}$ diameter. A sheet of stainless steel mash $50 \mathrm{~mm}$ long is wrapped around the DBD reactor's outer quartz glass wall serving as a ground electrode. $\mathrm{ZnO}, \mathrm{CuO}$, and $\mathrm{Fe}_{3} \mathrm{O}_{4}$ are chosen as catalysts with 1-3 mm particle sizes, which are packed in the DBD discharge region. The benzene-containing air is simulated by evaporating benzene through bubbling $\mathrm{N}_{2}$ in a water bath, which is then diluted with synthetic air in a mixing chamber. The initial concentration of benzene is fixed by controlling the temperature of the temperature-controlled bath and the $\mathrm{N}_{2}$ flow rate through a mass flow controller (D07series, Sevenstar, Beijing, China), which also controls the total synthetic air $\left(\mathrm{N}_{2}: \mathrm{O}_{2}=4: 1\right)$ with a $500 \mathrm{~mL} \cdot \mathrm{min}^{-1}$ flow rate. The discharge parameter of the DBD is obtained by an oscilloscope (TDS 3054B, Tektronix, Beaverton, OR, USA) coupled with a 1000:1 highvoltage probe (P6015A, Tektronix, Beaverton, OR, USA) and a 1:1 current monitor (A622, Tektronix, Beaverton, OR, USA). The OES are recorded by a grating spectrometer (DS-300122B, Acton, MA, USA). The concentrations of benzene, $\mathrm{CO}_{2}$ and $\mathrm{CO}$ are analyzed through gas chromatography (GC-7900, Techcomp, Shanghai, China). 


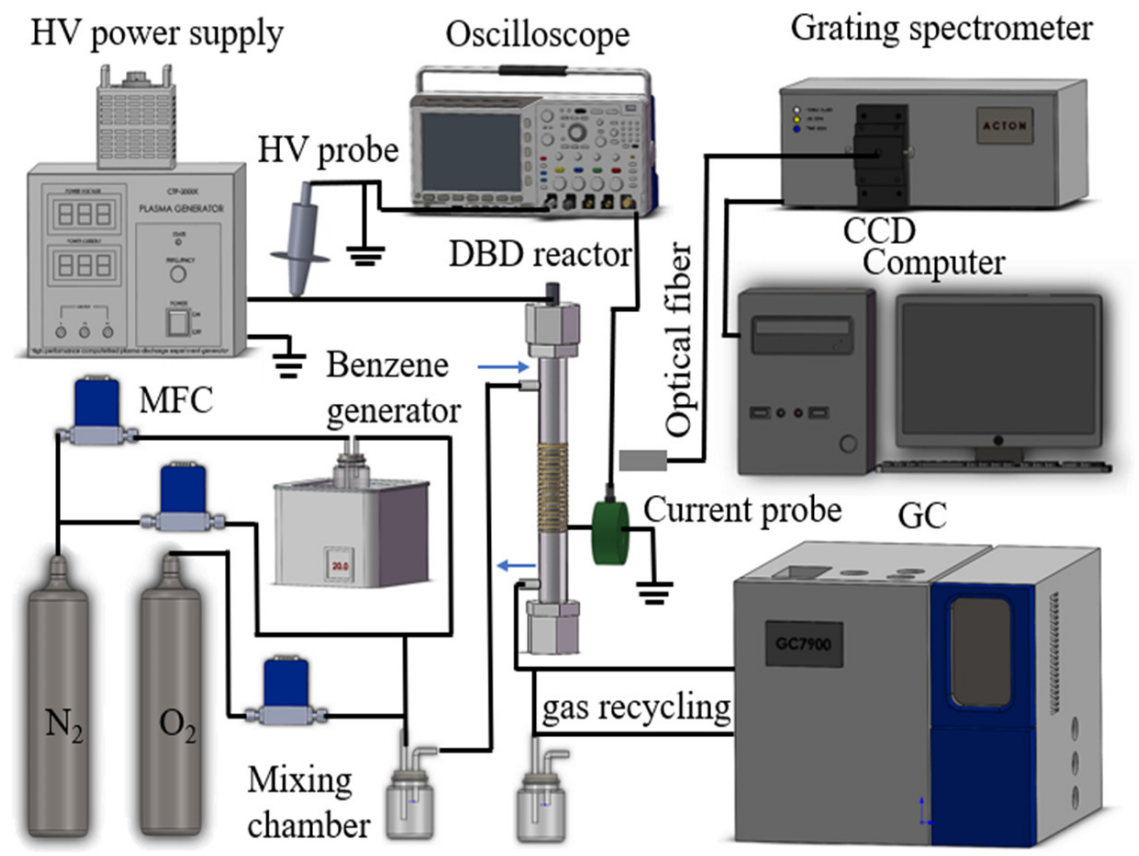

Figure 13. Schematic of the experimental setup for benzene degradation in a DBD reactor.

\subsection{Materials}

In this work, $\mathrm{CuO}, \mathrm{ZnO}$ and $\mathrm{Fe}_{3} \mathrm{O}_{4}$ were purchased from Beijing Zhong Nuo Xin Cai Scientific Co., Ltd., China. Benzene (99.5\%) was purchased from Shanghai Titan Scientific Co., Ltd., China.

\subsection{Catalyst Preparation}

Firstly, $17.5 \mathrm{~g}$ of anhydrous calcium chloride was dispersed in $232.5 \mathrm{~mL}$ deionized water, and then $40 \mathrm{~g} \mathrm{CuO} / \mathrm{ZnO} / \mathrm{Fe}_{3} \mathrm{O}_{4}$ powder was added to the solution; $2 \mathrm{~g}$ of alginic acid was dissolved in $98 \mathrm{~mL}$ deionized water and slowly added to the anhydrous calcium chloride mixture solution. After $2 \mathrm{~h}$ of stirring, the mixed solution was dropped onto 2-3 mm pellets via a peristaltic pump. Finally, the pellets were dried at $80{ }^{\circ} \mathrm{C}$ overnight, followed by calcining at $800{ }^{\circ} \mathrm{C}$ for $10 \mathrm{~h}$ using a muffle furnace.

\subsection{Chemical Analysis}

The performance of the benzene decomposition was evaluated by the factors of benzene removal efficiency ( $\left.\eta_{\text {benzene }}\right), \mathrm{CO}_{2}$ selectivity $\left(\mathrm{S}_{\mathrm{CO}_{2}}\right)$, specific input energy (SIE) and energy yield (EY), defined as:

$$
\begin{gathered}
\eta_{\text {benzene }}(\%)=\left(\frac{C_{\text {in }}-C_{\text {out }}}{C_{\text {in }}}\right) \times 100, \\
\mathrm{~S}_{\mathrm{CO}_{2}}(\%)=\frac{C_{\mathrm{CO}_{2}}}{\left(C_{\mathrm{CO}_{2}}+C_{\mathrm{CO}}\right)} \times 100, \\
\mathrm{SIE}(\mathrm{J} / \mathrm{L})=\frac{P}{Q} \times 60, \\
\mathrm{EY}(\mathrm{g} / \mathrm{kWh})=\frac{3.6 \times M \times\left(C_{\text {in }}-C_{\text {out }}\right)}{24.4 \times \mathrm{SIE}},
\end{gathered}
$$

where $C_{\text {in }}$ and $C_{\text {out }}$ present the inlet and outlet benzene concentrations (ppm). $C_{\mathrm{CO}_{2}}$ and $\mathrm{C}_{\mathrm{CO}}$ represent the concentrations of $\mathrm{CO}_{2}(\mathrm{ppm})$ and $\mathrm{CO}(\mathrm{ppm})$ at the outlet. $Q$ is the total flow rate $(\mathrm{L} / \mathrm{min})$ of the gas, and $P$ is the input power $(\mathrm{W})$. 
The classical Lissajous method is as follows [52]:

$$
\mathrm{I}(\mathrm{t})=\frac{\mathrm{d} q}{\mathrm{~d} t}=C \frac{\mathrm{d} U_{\mathrm{c}}}{\mathrm{d} t}
$$

where $C$ is the capacitance with $0.33 \mu \mathrm{F}, U_{\mathrm{C}}$ is the voltage of the capacitor, and $U_{\mathrm{HV}}$ is the voltage of the whole device.

$$
U_{\mathrm{t}}=U_{\mathrm{HV}}-U_{\mathrm{C}} \approx U_{\mathrm{HV}},
$$

since $U_{\mathrm{c}} \ll U_{\mathrm{HV}}$. So, the instantaneous power $P(\mathrm{~W})$ is:

$$
P(\mathrm{~W})=U_{\mathrm{t}} \times I_{\mathrm{t}} \approx U_{\mathrm{HV}}(\mathrm{t}) \times C \frac{\mathrm{d} U_{\mathrm{c}}}{\mathrm{d} t}
$$

Figure 14 shows the Lissajous figures of DBD packed with $\mathrm{ZnO} / \mathrm{CuO} / \mathrm{Fe}_{3} \mathrm{O}_{4}$. The applied voltage was $20 \mathrm{kV}$ and the driving frequency was $14 \mathrm{kHz}$. The Lissajous figures of DBD packed with three catalysts all resemble a parallelogram. The shapes of the Lissajous figures change with the types of filling materials, because of the different dielectric strengths of different catalysts [53]. It is indicated that $\mathrm{ZnO}$ and $\mathrm{CuO}$ transfers more charge than $\mathrm{Fe}_{3} \mathrm{O}_{4}$, judging from the slopes of the graph [54].

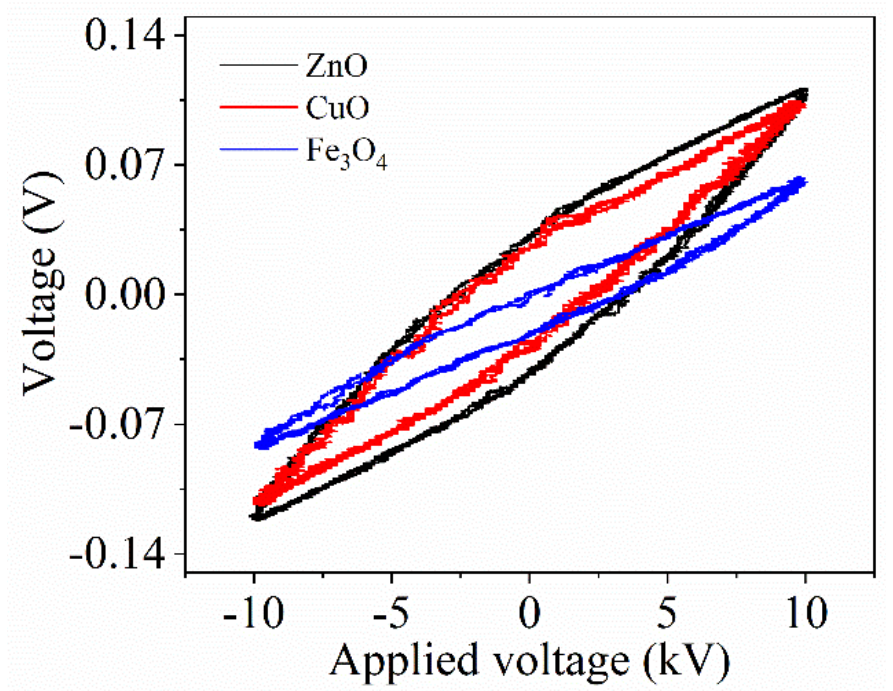

Figure 14. Lissajous figures of $\mathrm{DBD}$ packed with $\mathrm{ZnO} / \mathrm{CuO} / \mathrm{Fe}_{3} \mathrm{O}_{4}$ as the catalyst at $20 \mathrm{kV}$ and $14 \mathrm{kHz}$.

\section{Conclusions}

In this paper, a DBD reactor packed with transition metal oxide was employed to generate uniform plasma and degrade benzene. As the applied voltage increased, the discharge intensity was strongly enhanced. With the applied voltage and driving frequency increasing, the emission intensities of the three active species, $N_{2}\left(C^{3} \Pi_{u} \rightarrow B^{3} \Pi_{g}\right)$, $\mathrm{N}_{2}^{+}\left(\mathrm{B}^{2} \Sigma_{\mathrm{u}}^{+} \rightarrow \mathrm{X}^{2} \Sigma_{\mathrm{g}}^{+}\right)$, and $\mathrm{O}\left(3 p^{5} \mathrm{P} \rightarrow 3 s^{5} \mathrm{~S}_{2}^{\mathrm{o}}\right)$, were enhanced. The benzene degradation efficiency was promoted as the applied voltage and driving frequency increased, while EY decreased because part of the energy was lost as heat and light. With the initial benzene concentration increasing from $60 \mathrm{ppm}$ to $300 \mathrm{ppm}$, the degradation efficiency decreased from $100 \%$ to $52.3 \%$ under the conditions of $18 \mathrm{kV}$ applied voltage and a $14 \mathrm{kHz}$ driving frequency over the $\mathrm{ZnO}$ catalyst. Catalyst type can greatly influence the degradation efficiency of benzene; $\mathrm{CuO}$ has the best performance in terms of benzene conversion below $22 \mathrm{kV}$, while benzene's synergistic degradation with $\mathrm{ZnO}$ is better at higher applied voltages. When the initial concentration is 235 ppm, the applied voltage is $22 \mathrm{kV}$ and the driving 
frequency is $14 \mathrm{kHz}$, the degradation efficiencies of $\mathrm{CuO}, \mathrm{ZnO}$ and $\mathrm{Fe}_{3} \mathrm{O}_{4}$ are $93.6 \%, 93.2 \%$ and $76.2 \%$, respectively.

This paper also establishes the synergetic mechanisms of hybrid plasma/ZnO, plasma/ $\mathrm{CuO}$ and plasma $/ \mathrm{Fe}_{3} \mathrm{O}_{4}$, as well as the differences in the synergistic performance of transition metal oxides, conforming that the combination of plasma and transition metal oxides can effectively improve the removal of benzene.

Author Contributions: Data curation, D.Y.; methodology, D.Y. and H.Y.; validation, X.Z. and J.L.; formal analysis, Y.L. (Yuwei Li) and Y.L. (Yueyue Liu); investigation, Y.L. (Yuwei Li); resources, D.Y. and D.C.; writing—original draft preparation, Y.L. (Yuwei Li); writing-review and editing, D.Y., H.Y. and X.Z.; supervision, D.Y.; project administration, D.Y.; funding acquisition, D.Y. and D.C. All authors have read and agreed to the published version of the manuscript.

Funding: This research was funded by the National Natural Science Foundation of China, grant number 11965018, 50967018, and 52077026; the Science and Technology Development Fund of Xinjiang Production and Construction, grant number 2019BC009; the National Defense Science and Technology Key Laboratory Fund Project, grant number 6142605200303; the Science and Technology Plan Project of the Ninth Fund of Xinjiang Production and Construction, grant number 2021JS003; the Fundamental Research Funds for the Central Universities, grant number DUT21LK31.

Conflicts of Interest: The authors declare no conflict of interest.

\section{References}

1. Chang, T.; Shen, Z.X.; Huang, Y.; Lu, J.Q.; Ren, D.X.; Sun, J.; Cao, J.J.; Liu, H.X. Post-plasma-catalytic removal of toluene using $\mathrm{MnO} 2-\mathrm{Co} 3 \mathrm{O} 4$ catalysts and their synergistic mechanism. Chem. Eng. J. 2018, 348, 15-25. [CrossRef]

2. Xu, W.C.; Chen, B.X.; Jiang, X.D.; Xu, F.; Chen, X.; Chen, L.M.; Wu, J.L.; Fu, M.L.; Ye, D.Q. Effect of calcium addition in plasma catalysis for toluene removal by Ni/ZSM-5: Acidity/basicity, catalytic activity and reaction mechanism. J. Hazard. Mater. 2020, 387, 122004. [CrossRef] [PubMed]

3. Shou, T.Y.; Li, Y.N.; Bernards, M.T.; Becco, C.; Cao, G.H.; Shi, Y.; He, Y. Degradation of gas-phase o-xylene via combined non-thermal plasma and Fe doped LaMnO3 catalysts: Byproduct control. J. Hazard. Mater. 2020, 387, 121750. [CrossRef] [PubMed]

4. Mohammadi, P.; Ghorbani-Shahna, F.; Bahrami, A.; Rafati, A.A.; Farhadian, M. Plasma-photocatalytic degradation of gaseous toluene using SrTiO3/rGO as an efficient heterojunction for by-products abatement and synergistic effects. J. Photochem. Photobiol. A 2020, 394, 112460. [CrossRef]

5. Jiang, N.; Zhao, Y.H.; Shang, K.F.; Lu, N.; Li, J.; Wu, Y. Degradation of toluene by pulse-modulated multistage DBD plasma: Key parameters optimization through response surface methodology (RSM) and degradation pathway analysis. J. Hazard. Mater. 2020, 393, 122365. [CrossRef] [PubMed]

6. Jiang, N.; Hu, J.; Li, J.; Shang, K.F.; Lu, N.; Wu, Y. Plasma-catalytic degradation of benzene over Ag-Ce bimetallic oxide catalysts using hybrid surface/packed-bed discharge plasmas. Appl. Catal. B 2016, 184, 355-363. [CrossRef]

7. Mao, L.G.; Chen, Z.Z.; Wu, X.Y.; Tang, X.J.; Yao, S.L.; Zhang, X.M.; Jiang, B.Q.; Han, J.Y.; Wu, Z.L.; Lu, H.; et al. Plasmacatalyst hybrid reactor with $\mathrm{CeO}_{2} /$ gamma- $\mathrm{Al}_{2} \mathrm{O}_{3}$ for benzene decomposition with synergetic effect and nano particle by-product reduction. J. Hazard. Mater. 2018, 347, 150-159. [CrossRef]

8. Guo, H.; Liu, X.; Hojo, H.; Einaga, X.; Shangguan, W.F. Removal of benzene by non-thermal plasma catalysis over manganese oxides through a facile synthesis method. Environ. Sci. Pollut. Res. Int. 2019, 26, 8237-8247. [CrossRef] [PubMed]

9. Han, F.L.; Li, M.Y.; Zhong, H.G.; Li, T.; Li, D.D.; Zhou, S.; Guo, W.W.; Li, F. Product analysis and mechanism of toluene degradation by low temperature plasma with single dielectric barrier discharge. J. Saudi Chem. Soc. 2020, 24, 673-682.

10. Zhao, X.L.; Liu, X.; Liu, J.Q.; Chen, J.Y.; Fu, S.H.; Zhong, F.C. The effect of ionization energy and hydrogen weight fraction on the non-thermal plasma volatile organic compounds removal efficiency. J. Phys. D Appl. Phys. 2019, 52, 117945. [CrossRef]

11. Jiang, N.; Zhao, Y.H.; Qiu, C.; Shang, K.F.; Lu, N.; Li, J.; Wu, Y.; Zhang, Y. Enhanced catalytic performance of CoO-CeO 2 for synergetic degradation of toluene in multistage sliding plasma system through response surface methodology (RSM). Appl. Catal. B Environ. 2019, 259, 118061. [CrossRef]

12. Parvizi, N.; Rahemi, N.; Allahyari, S.; Tasbihi, M. Plasma-catalytic degradation of BTX over ternary perovskite-type La $1-x\left(C_{\text {, }}, Z_{\text {, }}\right.$ $\mathrm{Mg}, \mathrm{Ba})_{\mathrm{X}} \mathrm{MnO}_{3}$ nanocatalysts. J. Ind. Eng. Chem. 2020, 84, 167-178. [CrossRef]

13. Zhang, Q.Y.; Xie, L.X.; Lu, J.; Ma, Q.S.; Yu, Z.M.; Zhu, C.Z. Catalytic removal of gaseous styrene using DBD combined with $\mathrm{NiO} /$ Pyrite composite. Solid State Sci. 2020, 102, 106167. [CrossRef]

14. Nguyen, V.T.; Nguyen, D.B.; Heo, I.; Mok, Y.S. Efficient Degradation of Styrene in a Nonthermal Plasma-Catalytic System Over Pd/ZSM-5 Catalyst. Plasma Chem. Plasma Processing 2020, 40, 1207-1220. [CrossRef]

15. Veerapandian, S.K.P.; Leys, C.; De Geyter, N.; Morent, R. Abatement of VOCs Using Packed Bed Non-Thermal Plasma Reactors: A Review. Catalysts 2017, 7, 113. [CrossRef] 
16. Zhang, J.; Liu, Y.H.; Yao, X.H.; Shao, Q.; Xu, B.W.; Long, C. Enhanced moisture resistance of Cu/Ce catalysts for CO oxidation via Plasma-Catalyst interactions. Chemosphere 2020, 261, 127739. [CrossRef] [PubMed]

17. Liu, L.Z.; Sun, J.T.; Ding, J.D.; Zhang, Y.; Jia, J.P.; Sun, T.H. Catalytic Oxidation of VOCs over SmMnO 3 Perovskites: Catalyst Synthesis, Change Mechanism of Active Species, and Degradation Path of Toluene. Inorg. Chem. 2019, 58, 14275-14283. [CrossRef] [PubMed]

18. Yang, S.L.; Yang, H.C.; Yang, J.Y.; Qi, H.L.; Kong, J.; Bo, Z.; Li, X.D.; Yan, J.H.; Cen, K.F.; Tu, X. Three-dimensional hollow urchin $\alpha-\mathrm{MnO}_{2}$ for enhanced catalytic activity towards toluene decomposition in post-plasma catalysis. Chem. Eng. J. 2020, $402,126154$. [CrossRef]

19. Zhang, S.; Shen, X.J.; Liang, J.Y. Atmospheric pressure oxidation of dilute xylene using plasma-assisted MnOX catalysis system with different precursors. Mol. Catal. 2019, 467, 87-94. [CrossRef]

20. Yan, X.; Yi, C.W.; Wang, Y.H.; Cao, W.D.; Mao, D.N.; Ou, Q.Q.; Shen, P.Y.; Wang, H.J. Multi-catalysis of nano-zinc oxide for bisphenol A degradation in a dielectric barrier discharge plasma system: Effect and mechanism. Sep. Purif. Technol. 2020, 231, 115897. [CrossRef]

21. Rostami, R.; Moussavi, G.; Darbari, S.; Jafari, A.J. Non-thermal plasma by positive corona glow discharge using nano-structured $\mathrm{Cu} / \mathrm{CuO}$ coated electrodes for benzene removal from air flow; removal enhancement and energy efficiency improvement. Sep. Purif. Technol. 2021, 275, 119156. [CrossRef]

22. Gadkari, S.; Gu, S. Influence of catalyst packing configuration on the discharge characteristics of dielectric barrier discharge reactors: A numerical investigation. Phys. Plasmas 2018, 25, 063513. [CrossRef]

23. Li, Y.; Yang, D.Z.; Qiao, J.J.; Zhang, L.; Wang, W.Z.; Zhao, Z.L.; Zhou, X.F.; Yuan, H.; Wang, W.C. The dynamic evolution and interaction with dielectric material of the discharge in packed bed reactor. Plasma Sources Sci. Technol. 2020, 29, 055004. [CrossRef]

24. Abdelaziz, A.A.; Ishijima, T.; Seto, T. Humidity effects on surface dielectric barrier discharge for gaseous naphthalene decomposition. Phys. Plasmas 2018, 25, 043512. [CrossRef]

25. Yu, X.; Dang, X.Q.; Li, S.J.; Zhang, J.L.; Zhang, Q.; Cao, L. A comparison of in- and post-plasma catalysis for toluene abatement through continuous and sequential processes in dielectric barrier discharge reactors. J. Clean. Prod. 2020, 276, 124251. [CrossRef]

26. Shang, K.F.; Wang, M.W.; Peng, B.F.; Li, J.; Lu, N.; Jiang, N.; Wu, Y. Characterization of a novel volume-surface DBD reactor: Discharge characteristics, ozone production and benzene degradation. J. Phys. D Appl. Phys. 2020, 53, 121638. [CrossRef]

27. Li, S.J.; Dang, X.Q.; Yu, X.; Yu, R.; Abbasd, G.; Zhang, Q. High energy efficient degradation of toluene using a novel double dielectric barrier discharge reactor. J. Hazard. Mater. 2020, 400, 123259. [CrossRef]

28. Zhang, L.; Yang, D.Z.; Wang, W.C.; Wang, S.; Yuan, H.; Zhao, Z.L.; Sang, C.F.; Jia, L. Needle-array to Plate DBD Plasma Using Sine $\mathrm{AC}$ and Nanosecond Pulse Excitations for Purpose of Improving Indoor Air Quality. Sci. Rep. 2016, 6, 25242. [CrossRef]

29. Kozlov, K.V.; Brandenburg, R.; Wagner, H.E.; Morozov, A.M.; Michel, P. Investigation of the filamentary and diffuse mode of barrier discharges in N2/O2mixtures at atmospheric pressure by cross-correlation spectroscopy. J. Phys. D Appl. Phys. 2005, 38, 518-529. [CrossRef]

30. Zhang, S.; Wang, W.C.; Yang, D.Z.; Yuan, H.; Zhao, Z.L.; Sun, H.; Shao, T. Nanosecond pulsed uniform dielectric barrier discharge in atmospheric air: A brief spectroscopic analysis. Spectrochim. Acta A Mol. Biomol. Spectrosc. 2019, 207, 294-300. [CrossRef]

31. Yang, D.Z.; Yang, Y.; Li, S.Z.; Nie, D.X.; Zhang, S.; Wang, W.C. A homogeneous dielectric barrier discharge plasma excited by a bipolar nanosecond pulse in nitrogen and air. Plasma Sources Sci. Technol. 2012, 21, 035004. [CrossRef]

32. Liu, Z.J.; Wang, W.C.; Zhang, S.; Yang, D.Z.; Jia, L.; Dai, L.Y. Optical study of a diffuse bipolar nanosecond pulsed dielectric barrier discharge with different dielectric thicknesses in air. Eur. Phys. J. D 2012, 66, 319. [CrossRef]

33. Liang, J.P.; Zhou, X.F.; Zhao, Z.L.; Yang, D.Z.; Wang, W.C. Degradation of trimethoprim in aqueous by persulfate activated with nanosecond pulsed gas-liquid discharge plasma. J. Environ. Manage. 2021, 278, 111539. [CrossRef] [PubMed]

34. Li, M.Y.; Li, D.D.; Zhang, Z.Q.; Ji, C.J.; Zhou, S.; Guo, W.W.; Zhao, C.C.; Liu, F.; Han, F.L. Study on the performance and mechanism of degradation of toluene with non-thermal plasmas synergized supported $\mathrm{TiO}_{2} / \gamma-\mathrm{Al}_{2} \mathrm{O}_{3}$ catalyst. J. Environ. Chem. Eng. 2021, 9 , 105529. [CrossRef]

35. Liang, W.J.; Sun, H.P.; Shi, X.J.; Zhu, Y.X. Abatement of Toluene by Reverse-Flow Nonthermal Plasma Reactor Coupled with Catalyst. Catalysts 2020, 10, 511. [CrossRef]

36. Ruan, Y.X.; Guo, H.; Li, J.; Liu, Z.Y.; Jiang, N.; Wu, Y. Enhanced removal of toluene by pulse discharge plasma coupled with MgO cathode and graphene Mn-Ce bimetallic oxide. Chemosphere 2020, 258, 127334. [CrossRef]

37. Norsic, C.; Tatibouët, J.M.; Batiot-Dupeyrat, C.; Fourré, E. Non thermal plasma assisted catalysis of methanol oxidation on Mn, $\mathrm{Ce}$ and $\mathrm{Cu}$ oxides supported on $\gamma-\mathrm{Al}_{2} \mathrm{O}_{3}$. Chem. Eng. J. 2016, 304, 563-572. [CrossRef]

38. Ye, H.L.; Liu, Y.Q.; Chen, S.; Wang, H.Q.; Liu, Z.; Wu, Z.B. Synergetic effect between non-thermal plasma and photocatalytic oxidation on the degradation of gas-phase toluene: Role of ozone. Chin. J. Catal. 2019, 40, 631-637. [CrossRef]

39. Wang, C.Y.; Zhu, L.; Zhao, F.; Xu, D.Y. The chemistry of gaseous benzene degradation using non-thermal plasma. Environ. Sci. Pollut. Res. Int. 2021, 28, 1565-1573. [CrossRef]

40. Yang, D.Z.; Jia, L.; Wang, W.C.; Wang, S.; Jiang, P.C.; Zhang, S.; Yu, Q.X.; Chen, G.L. Atmospheric Pressure Gas-Liquid Diffuse Nanosecond Pulse Discharge Used for Sterilization in Sewage. Plasma Process. Polym. 2014, 11, 842-849. [CrossRef]

41. Wu, Z.L.; Zhu, Z.B.; Hao, X.D.; Zhou, W.L.; Han, J.Y.; Tang, X.J.; Yao, S.L.; Zhang, X.M. Enhanced oxidation of naphthalene using plasma activation of $\mathrm{TiO}_{2}$ /diatomite catalyst. J. Hazard. Mater. 2018, 347, 48-57. [CrossRef] 
42. Liu, J.; Wang, P.L.; Qu, W.Q.; Li, H.R.; Shi, L.Y.; Zhang, D.S. Nanodiamond-decorated ZnO catalysts with enhanced photocorrosionresistance for photocatalytic degradation of gaseous toluene. Appl. Catal. B Environ. 2019, 257, 117880. [CrossRef]

43. Zeng, S.H.; Wang, Y.; Ding, S.P.; Sattler, J.J.H.B.; Borodina, E.; Zhang, L.; Weckhuysen, B.M.; Su, H.Q. Active sites over CuO/CeO 2 and inverse $\mathrm{CeO}_{2} / \mathrm{CuO}$ catalysts for preferential CO oxidation. J. Power Sources 2014, 256, 301-311. [CrossRef]

44. Tisseraud, C.; Comminges, C.; Habrioux, A.; Pronier, S.; Pouilloux, Y.; Valant, A.L. Cu-ZnO catalysts for $\mathrm{CO}_{2}$ hydrogenation to methanol: Morphology change induced by ZnO lixiviation and its impact on the active phase formation. Mol. Catal. 2018, 446, 98-105. [CrossRef]

45. Xie, W.L.; Han, Y.X.; Wang, H.Y. Magnetic Fe3O4/MCM-41 composite-supported sodium silicate as heterogeneous catalysts for biodiesel production. Renew. Energy 2018, 125, 675-681. [CrossRef]

46. Liu, J.X.; Wang, L.; Okejiri, F.; Luo, J.; Zhao, J.H.; Zhang, P.F.; Liu, M.M.; Yang, S.Z.; Zhang, Z.H.; Song, W.Y.; et al. Deep Understanding of Strong Metal Interface Confinement: A Journey of Pd/FeOx Catalysts. ACS Catal. 2020, 10, 8950-8959. [CrossRef]

47. Mei, D.H.; Zhu, X.B.; Wu, C.F.; Ashford, B.; Williams, P.T.; Tu, X. Plasma-photocatalytic conversion of $\mathrm{CO}_{2}$ at low temperatures: Understanding the synergistic effect of plasma-catalysis. Appl. Catal. B Environ. 2016, 182, 525-532. [CrossRef]

48. Hu, J.; Jiang, N.; Li, J.; Shang, K.F.; Lu, N.; Wu, Y. Degradation of benzene by bipolar pulsed series surface/packed-bed discharge reactor over $\mathrm{MnO}_{2}-\mathrm{TiO}_{2}$ / zeolite catalyst. Chem. Eng. J. 2016, 293, 216-224. [CrossRef]

49. Li, J.; Zhu, S.J.; Lu, K.; Ma, C.H.; Yang, D.Z.; Yu, F. CO 2 conversion in a coaxial dielectric barrier discharge plasma reactor in the presence of mixed $\mathrm{ZrO}_{2}-\mathrm{CeO}_{2}$. J. Environ. Chem. Eng. 2021, 9, 104654. [CrossRef]

50. Liu, R.Q.; Song, H.; Li, B.; Li, X.; Zhu, T.L. Simultaneous removal of toluene and styrene by non-thermal plasma-catalysis: Effect of VOCs interaction and system configuration. Chemosphere 2021, 263, 127893. [CrossRef]

51. Liang, Y.T.; Li, J.Y.; Xue, Y.Y.; Tan, T.; Jiang, Z.; He, Y.Y.; Shangguan, W.F.; Yang, J.Z.; Pan, Y. Benzene decomposition by non-thermal plasma: A detailed mechanism study by synchrotron radiation photoionization mass spectrometry and theoretical calculations. J. Hazard. Mater. 2021, 420, 126584. [CrossRef] [PubMed]

52. Yuan, H.; Wang, W.C.; Yang, D.Z.; Zhao, Z.L.; Zhang, L.; Wang, S. Atmospheric air dielectric barrier discharge excited by nanosecond pulse and AC used for improving the hydrophilicity of aramid fibers. Plasma Sci. Technol. 2017, 19, 125401. [CrossRef]

53. Zhu, S.J.; Zhou, A.M.; Yu, F.; Dai, B.; Ma, C.H. Enhanced $\mathrm{CO}_{2}$ decomposition via metallic foamed electrode packed in self-cooling DBD plasma device. Plasma Sci. Technol. 2019, 21, 0636. [CrossRef]

54. Li, J.; Zhai, X.W.; Ma, C.H.; Zhu, S.J.; Yu, F.; Dai, B.; Ge, G.X.; Yang, D.Z. DBD Plasma Combined with Different Foam Metal Electrodes for $\mathrm{CO}_{2}$ Decomposition: Experimental Results and DFT Validations. Nanomaterials 2019, 9, 1595. [CrossRef] 